\title{
REVISTA DE ARQUEOLOGIA
}

Volume 32 No. 12019

\section{AS INDÚSTRIAS LÍTICAS ANTIGAS DE SERRANÓPOLIS \\ [SÍTIOS G0-JA-03 E GO-JA-14]}

Maria Jacqueline Rodet ${ }^{\star}$, Déborah Duarte-Talim ${ }^{\star *}$, Pedro Ignácio Schmitz ${ }^{\star \star \star}$

RESUMO

Os vestígios líticos do sítio GO-JA-03, Serranópolis, estado de Goiás, apresentam uma produção de grandes lascas alongadas, mais e menos espessas, retiradas com percussão de pedra macia ou percussão orgânica tangencial, com procedimentos técnicos muito específicos nas proximidades do talão, as quais servirão de suporte para instrumentos unifaciais de secção plano-convexa. $\mathrm{O}$ método de análise compreendeu o conceito de Cadeia Operatória, que considera os instrumentos desde o seu abandono, passando por todas as fases de produção. Os resultados obtidos demonstram uma indústria bem estruturada com um alto nível de savoirfaire.

Palavras-chave: Tecnologia lítica; Brasil Central; Serranópolis.

* Professora Associada da Universidade Federal de Minas Gerais, Faculdade de Filosofia e Ciências Humanas, Departamento de Antropologia - Av. Pres. Antônio Carlos, 6627 - Pampulha, Belo HorizonteMG, 31270-901. CNPq; Fapemig. E-mail: mjrodet.ufmg@gmail.com. https://orcid.org/0000-0001-57425999.

** Doutoranda Universidade Federal de Minas Gerais, Faculdade de Filosofia e Ciências Humanas, Departamento de Antropologia - R. Tumucumaques, 85, bl3, apto 404 - Santa Mônica, Belo HorizonteMG, 31530-180. Bolsista Fapemig. E-mail: delsduarte@hotmail.com. http://orcid.org/0000-0002-5470$\underline{3364 .}$.

*** Coordenador da Arqueologia do Instituto Anchietano de Pesquisas - Universidade do Vale do Rio dos Sinos, Instituto Anchietano de Pesquisas. Avenida Unisinos, 950 - Cristo Rei, São Leopoldo-RS, 93022000. E-mail: anchietano@unisinos.br. http://orcid.org/0000-0003-4619-8668. 


\section{THE ANCIENT LITHIC INDUSTRIES OF SERRANÓPOLIS \\ [SITES G0-JA-03 AND G0-JA-14]}

\section{ABSTRACT}

The lithic vestiges of GO-JA-03 site, Serranópolis, state of Goiás, Brazil, present large, thin, elongated flakes knapped with soft stone percussion or tangential organic percussion, with very specific technical procedures near the butt. These flakes will serve as support for unifacial artifacts (flat-convex section). The method of analysis included the concept of the Chaïne Opératoire, which considers the instruments from their abandonment through all phases of production. The results demonstrate a well-structured industry with a high level of savoir-faire.

Keywords: Technological approach; Central Brazil region; Serranópolis.

\section{LAS INDUSTRIAS LÍTICAS ANTIGUAS DE SERRANÓPOLIS [SITIOS GO-JA-03 Y GO-JA-14]}

RESUMEN

Los vestigios líticos del sitio GO-JA-03, Serranópolis, estado de Goiás, presentan una producción de grandes lascas alargadas, más y menos espesas, retiradas con percusión de piedra blanda o percusión orgánica tangencial, con procedimientos técnicos muy específicos en las proximidades del talón, que servirán de soporte para instrumentos unifaciales de sección plano-convexa. El método de análisis comprendió el concepto de Cadena Operativa que considera los instrumentos desde su abandono pasando por todas las fases de producción. Los resultados obtenidos demuestran una industria bien estructurada con un alto nivel de savoirfaire.

Palabras clave: Tecnología lítica; Brasil Central; Serranópolis. 


\section{INTRODUÇÃO}

A região de Serranópolis encontra-se no sudoeste do estado de Goiás, sendo uma importante área com sítios arqueológicos que se insere no contexto do Brasil Central. O setor apresenta uma vegetação tipicamente de cerrado, sustentada por um substrato rochoso de Arenito Botucatu, com altas temperaturas e duas estações muito bem definidas ao longo do ano (estação chuvosa e estação seca). As pesquisas sistemáticas na região de Serranópolis começaram no ano de 1975, sob a direção do P. I. Schmitz, tendo sido encontrados 40 sítios sob abrigo em uma área de $20 \times 30 \mathrm{~km}$, em uma altitude entre $950 \mathrm{~m}$ e $500 \mathrm{~m}$. As datas mais antigas situam as ocupações no início do período Holoceno, sendo as mais antigas de $10.580 \pm 1150$ B.P (Cal BP 12.744-11.834 anos ${ }^{1}$ ) e as mais recentes de $925 \pm 60$ BP (Cal B.P.956-667 anos), no sítio GO-JA-01 (SCHMITZ et al., 2004), demonstrando uma ocupação de longa duração no setor. As escavações foram realizadas por níveis artificiais de $10 \mathrm{~cm}$ : trata-se, em grande parte, de um sedimento composto por uma areia muito fina (decomposição da rocha encaixante, materiais antropogênicos), difícil de manter in situ durante as escavações. Os vestígios exumados podem ser sintetizados em: uma grande quantidade de vestígios líticos, materiais orgânicos, tais como milho, algodão, restos de frutas, cordas e folhas, etc., além de fragmentos cerâmicos nos níveis superiores e em superfície. As paredes dos abrigos estão cobertas por pinturas e gravuras (SCHMITZ et al., 2004).

Nosso interesse são as indústrias líticas antigas e as intenções tecnológicas das produções dos grupos no período. Nesse sentido, o sítio GO-JA-03, o maior dos sítios do grupo D (fig. 1), parece ter uma coleção lítica muito especifica (área com acúmulo de restos de debitagem), a qual poderá contribuir para responder às nossas indagações. Trata-se de um grande abrigo, exposto à leste (recebendo o sol da manhã), formado pela inclinação das camadas de arenito, algumas altamente silicificadas, o que dá ao local uma importância no que se refere à matéria-prima de excelente qualidade para o lascamento. No centro do abrigo há uma plataforma, acessível através de uma fissura da rocha. Ao que parece, o local foi sistematicamente utilizado pelos lascadores e lascadoras. O Corte IV, realizado na base dessa plataforma, demonstra um acúmulo de restos de lascamento ao longo de dez camadas estratigráficas que atingem $220 \mathrm{~cm}$ de profundidade (fig. 2). Esses restos estão ligados às ocupações que são datadas de 9.765 \pm 75 BP (Cal BP 11.35910.714 anos - nível 210-220 cm, Fase Paranaíba) e de 5.720 5 50 BP (Cal BP 6.657-6.302 anos - nível 150-160 cm - SCHMITZ et al., 2004). Nesse sentido, as coleções exumadas do setor são específicas e trazem em si informações chaves para a compreensão das escolhas técnicas da produção.

O objetivo principal deste trabalho é buscar através dos vestígios exumados do Corte IV, as intenções das produções humanas presentes nessas indústrias líticas. Quais regras culturais (econômicas e técnicas), regeram e estruturam a produção de certos instrumentos líticos presentes no sítio? Paralelamente, pretende-se demonstrar que os conceitos da Escola Francesa são um instrumento eficaz para a compreensão das intenções inscritas nas indústrias líticas.

\footnotetext{
${ }^{1}$ A calibração das datas presentes neste artigo foi feita através do programa online OxCal V.4.3.2 (RAMSEY, 2009), baseada na curva SHCal-13 (HOGG et al., 2013), adotando-se um nível de probabilidade de 95\% (2 sigma).
} 
Figura 1 - Mapa de localização dos sítios e planta: o sítio GO-JA-03 se situa na margem do córrego Grotão, no grupo D, enquanto o GO-JA-14 no grupo F, aproximadamente $6 \mathrm{~km}$. O sítio GO-JA-01 situa-se à aproximadamente $20 \mathrm{~km}$ ao norte do grupo D (SCHMITZ et al., 2004, modificado por $\mathrm{H}$. Talim). Os cortes C4 e C7 foram objeto da análise apresentada neste artigo. Notar pequeno patamar rochosos, terracete. O acesso ao local se faz por uma pequena passagem (SCHMITZ et al., 2004, modificado por MORENO DE SOUSA, 2014).
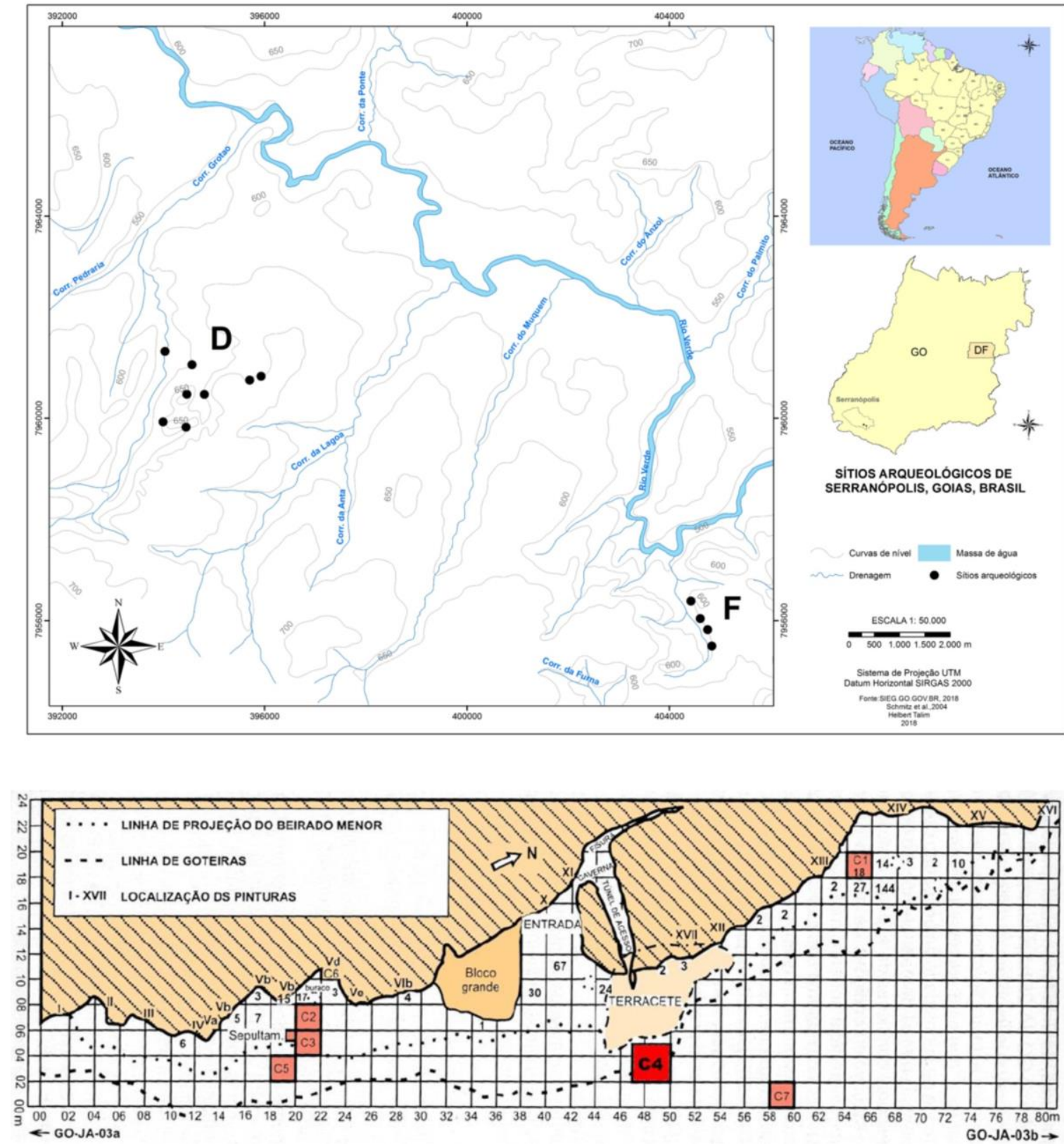

\section{PROBLEMÁTICA GERAL DAS INDÚSTRIAS ANTIGAS DO BRASIL CENTRAL}

Dentre as questões que permeiam o debate sobre as populações antigas que frequentaram o Brasil central, nos interessam aquelas relacionadas à homogeneidade tecnológica das indústrias líticas. Esse ponto de vista de uma conformidade tecnológica no período é bem marcado na bibliografia pela utilização sistemática do termo "Tradição Itaparica”, que denomina as ocupações com instrumentos unifaciais de secção planoconvexa presentes nos sítios arqueológicos do Brasil Central durante os períodos antigos. Essa região abarca os atuais estados de Minas Gerais, Bahia, Pernambuco, Rio de Janeiro, Espírito Santo, Goiás e Tocantins, compreendendo uma área de mais de dois mil 
quilômetros quadrados. Entretanto nossa ideia é que, mais do que uma homogeneidade, existe, de fato, para a região do Brasil Central, uma heterogeneidade nas produções líticas ao longo das primeiras ocupações, a qual continua ao longo do período do Holoceno.

Para melhor compreender a discussão, é fundamental rever a questão da criação do termo e recolocá-lo em seu contexto metodológico. O termo "Tradição Itaparica" foi criado por V. Calderón nos anos 1960 (1965-1966;1969;1983), a partir de indústrias encontradas na gruta do Padre, no estado de Pernambuco, durante as atividades do Programa Nacional de Arqueologia (PRONAPA), que teve como um dos objetivos uma classificação e um conhecimento geral da arqueologia nacional.

Nessa perspectiva, durante os anos 1965 a 1970, os trabalhos de campo foram realizados a partir de uma metodologia padronizada de prospecções de um máximo de sítios arqueológicos, nas distintas regiões do Brasil (exceto Amazônia, que será contemplada mais tarde, entre os anos 1977 e 1981). Os materiais exumados foram organizados por seriação em categorias denominadas "tradições", "fases" e sub-fases" e localizados no tempo, num primeiro momento, por datações relativas e, mais tarde, por 14C (BARRETO, 1999-2000). Tais categorias foram definidas pelos mentores intelectuais desse trabalho, os americanos P. Philipps e G. Willey (1953), e aplicados tanto no contexto da América do norte como na América do Sul.

No Brasil, o trabalho foi financiado pelo Smithsonian Institute, pelo Conselho Nacional do Desenvolvimento Científico e Tecnológico, CNPq e pela Secretaria do Patrimônio Artístico e Nacional (SPHAN, mais tarde IPHAN). Os coordenadores do projeto no Brasil, os pesquisadores B. Meggers e C. Evans, contaram com a participação de arqueólogos brasileiros de diversos estados (BARRETO, 1999-2000; RODET et al., 2011).

$\mathrm{Na}$ perspectiva americana dos autores, a taxonomia, muito utilizada nas ciências biológicas, é um método básico e pode ser empregado em todas as ciências. Assim sendo, vão aplicá-lo à arqueologia e estabelecer diferentes categorias classificatórias (taxonômicas) dos vestígios, criando uma tipologia que, no caso, terá os grandes unifaciais de secção plano-convexa como guia (RODET et al., 2011). Em complemento, havia a ideia de que, nesse momento inicial da ocupação da região, os grupos não possuíam instrumentos bifaciais.

Nesse contexto teórico-metodológico da escola Americana, a definição realizada para as indústrias da gruta do Padre apresenta alguns limites no que concerne à sua aplicação ao conjunto do Brasil Central, quais sejam, i. trata-se de estudos baseados em análises tipológicas e não tecno-econômicas; ii. tendo como conceito os fósseis guias, no caso os unifaciais de seção plano-convexa realizados sobre seixos; iii. por outro lado, as datações mais antigas da gruta colocam-na no período do Holoceno médio. Portanto relacioná-las diretamente às indústrias de populações dos períodos Pleistoceno e Holoceno inicial (como vem sendo feito sistematicamente no Brasil), sem uma ampla discussão, pode não ser metodologicamente apreciável.

Assim, apesar de parecer bem localizada no tempo e no espaço, o termo "Tradição Itaparica" não define bem os distintos componentes das indústrias e menos ainda sua temporalidade. Em contrapartida, ele homogeneíza as distintas produções de um longo período.

Por outro lado, os métodos mais recentes de análises, baseados nos conceitos de cadeia operatória, análise tecno-econômica, economia da debitagem e savoir-faire (MAUSS, 1947; MAGET, 1953; LEROI-GOURHAN, 1964; TIXIER, 1967, 1980 [1984]; PERLÈS, 1980; PELEGRIN, 1986 [1995]; BOËDA, 1990; PIGEOT, 1991; INIZAN et al., 2017; dentre outros), apesar de terem começado a ser aplicados no Brasil, quase uma década mais tarde, permitem uma compreensão mais ampla das escolhas e das intenções 
humanas presentes nos instrumentos e objetos produzidos pelos grupos ao longo do tempo. Nesse sentido, ao considerar diversos estudos realizados em áreas do Brasil Central (FOGAÇA, 2001; RODET, 2006; BUENO, 2007; ISNARDIS, 2009; RODET, 2009; LOURDEAU, 2010; RODET et al., 2011; BASSI \& RODET, 2011; MARTINS \& KASHIMOTO, 2012; BASSI, 2012; DIAS \& BUENO, 2013; RODET \& DUARTETALIM, 2013; KOOLE, 2014; MORENO DE SOUSA, 2014; VIEIRA et al., 2015; entre outros), foi possível observar que, contrariamente a uma uniformidade, parece existir uma grande variedade de escolhas para as produções de instrumentos unifaciais, as quais convivem ao mesmo tempo em diferentes áreas do Brasil Central. Observa-se que: as matérias-primas (arenitos, quartzitos, quartzos, etc.), os suportes (lascas, seixos, plaquetas, etc.), as técnicas (percussão direta dura ou macia, percussão sobre bigorna, etc.), assim como métodos distintos foram selecionados nas diversas produções líticas. Ainda, inversamente ao que foi definido para o período, nota-se a presença de uma indústria bifacial, também diversificada, ao longo de todo período. Foram observadas produções de grandes peças bifaciais (vale do rio Peruaçu, Serranópolis, etc.), assim como uma diversificação na produção de pontas de projétil (FOGAÇA, 2001; RODET, 2006, 2009; ISNARDIS, 2009; BASSI, 2011; KOOLE, 2014; RODET et al., no prelo; entre outros).

Mesmo se pleiteamos uma heterogeneidade nas produções antigas, é importante apresentar os pontos comuns que se sobressaem, quais sejam: a busca por instrumentos de seção plano-convexa, com alta disponibilidade de gumes utilizáveis, realizados sobre lascas alongadas ou, ainda, a escolha de matérias-primas que respondem bem ao lascamento, para a produção de instrumentos mais elaborados (RODET et al., no prelo).

Finalmente, acreditamos que a abordagem tecno-econômica, utilizada cada vez mais na América do Sul, traz um enfoque mais amplo e permite compreender o objeto final, o instrumento, desde a ideia de sua concepção até o seu abandono, considerando todas as suas fases de produção. Nesse sentido, o estudo aqui apresentado pretende contribuir para esclarecer um pouco mais a questão da heterogeneidade das indústrias desse período. Pretende-se demonstrar que a produção realizada no setor estudado aponta para a utilização de duas técnicas bem especificas para retirada de grandes lascas alongadas, até então não descritas na bibliografia, as quais serão transformadas em instrumentos unifaciais. Trata-se de um alto nível de savoir-faire aplicado a uma matériaprima de qualidade para o lascamento. Escolhas bem especificas e distintas de outros setores do Brasil Central, demonstrando a diversidade de suas indústrias.

\section{A COLEÇÃO ESTUDADA}

A coleção, exumada do Corte IV (2,5 x 2,5 cm e 2,40 m de profundidade), provém principalmente dos níveis antigos (15 a 24) do grande sítio GO-JA-03 (fig. 2). Trata-se dos vestígios líticos dos níveis profundos, relacionados ao que é denominado Fase Paranaíba, os quais apresentam um total de 81.624 peças (níveis 15 a 24), entre instrumentos, núcleos e brutos de debitagem (SCHMITZ et al., 2004: 31). Somente uma parte da coleção foi estudada e é objeto deste artigo (níveis 21 a 24) em função das datações, realizadas a partir no nível 21 , demonstrando claramente a antiguidade dos níveis escolhidos. Em função da grande quantidade de pequenas lascas tecnomorfologicamente similares (realizadas em arenito silicificado, homogêneo, dimensões entre 2 e $4 \mathrm{~cm}$, morfologia tendendo a quadrangular, talões lisos, sistematicamente abrasados, sem acidentes; face superior com retiradas na mesma direção ou ligeiramente deslocada), foi realizado um recorte amostral visual de aproximadamente $50 \%$ dessas lascas (aproximadamente $2 \mathrm{~kg}$ de material) e foram analisadas por volta de 2.400 peças (instrumentos, lascas de debitagem, façonagem e retoque), além de $2.190 \mathrm{~kg}$ de pequenas 
lascas analisadas, mas não contabilizadas. Em contrapartida, os instrumentos foram todos analisados, trata-se de 4 instrumentos unifaciais; 1 instrumento bifacial e 22 instrumentos simples ${ }^{2}$, pouco transformados (unifacialmente e bifacialmente). Serão apresentados aqui os principais resultados relacionados aos vestígios com informações tecnológicas mais relevantes. Para complementar o estudo, foram considerados um instrumento exumado do Corte VII (nível 31 - GO-JA-03), próximo ao Corte IV e dois outros instrumentos provenientes dos níveis antigos do sítio GO-JA-14, localizado nas proximidades (figs. 1e 2).

Figura 2 - Estratigrafia dos sítios analisados: tanto o sítio GO-JA-03 quanto o GO-JA-14 apresentam longa sequência estratigráfica, com vestígios nos diferentes momentos de ocupação do setor (Adaptado de SCHMITZ et al., 2004).

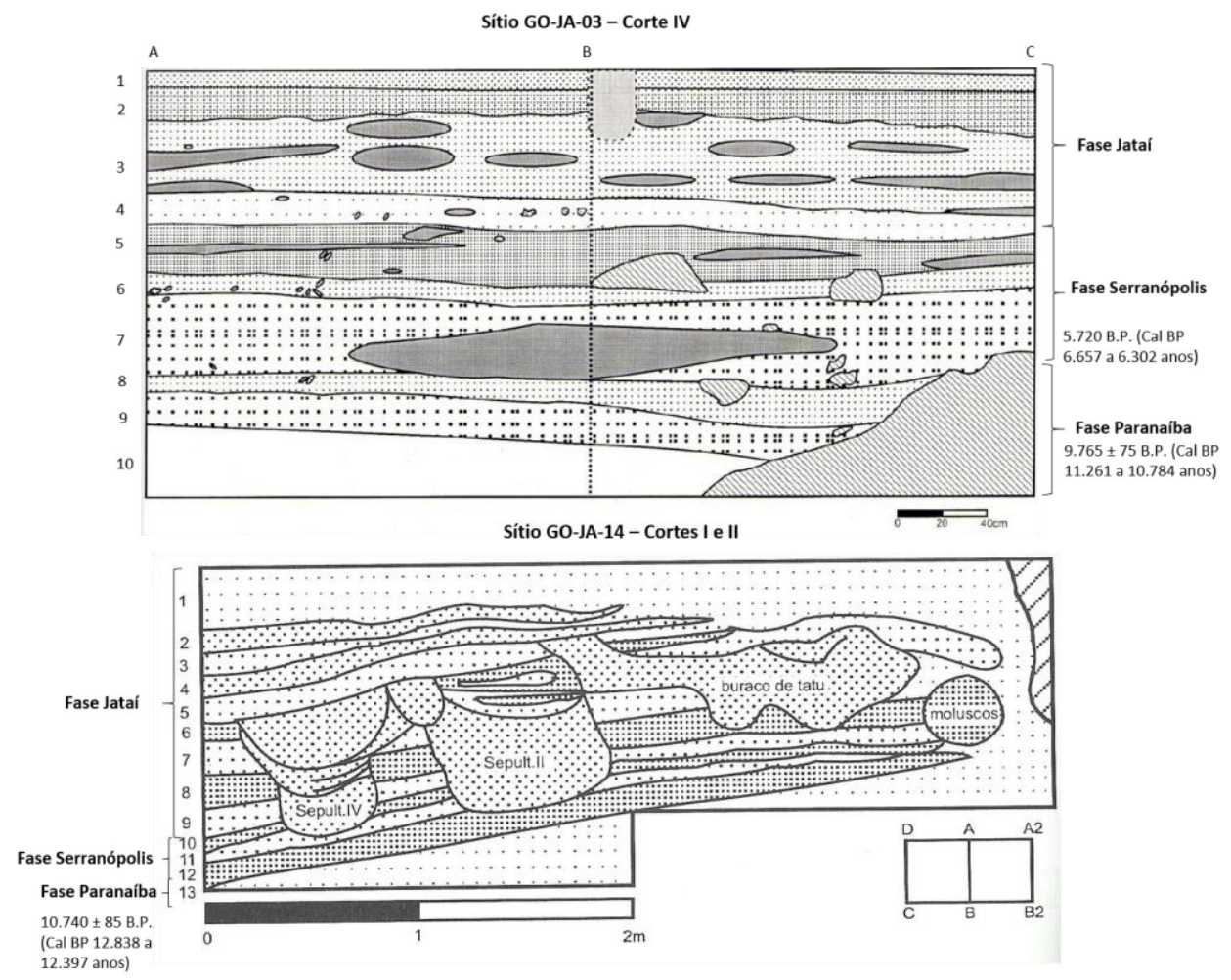

De acordo com P. I. Schmitz e colegas (2004), a matéria-prima utilizada na coleção é principalmente o arenito silicificado ou quartzito (80.415 peças - 98,84\%), seguida por calcedônia (938 peças - 1,15\%), basalto $(7,0$ - 0,08\%) e matérias-primas variadas (14 0,001\%). O arenito é de excepcional qualidade para o lascamento e está presente na rocha encaixante do abrigo ou nas torres residuais do entorno e foi sistematicamente utilizado ao longo das ocupações. A calcedônia (variados materiais criptocristalinos ou de estrutura fina) tem sua origem no basalto e pode ser encontrada na proximidade dos abrigos. Os basaltos, com espessura considerável, atualmente são observados na margem

\footnotetext{
${ }^{2}$ Instrumento simples é um termo escolhido para se opor a instrumento elaborado. Enquanto alguns instrumentos têm uma longa cadeia operatória de produção, passando por distintas fases, com trocas de técnicas e um produto final podendo ser totalmente diferente do suporte inicial; os instrumentos simples têm poucas transformações. Em geral, trata-se de lascas ou fragmentos que recebem algumas poucas modificações no gume: alguns retoques em setores específicos do suporte que servem para regularizar parte de um bordo, tornando-o mais apto a uma determinada ação (seja cortar, raspar, furar, etc.). Utiliza-se sempre a mesma técnica (em geral percussão direta dura), podendo ser retoques diretos, inversos, ocupando um gume ou vários, mas sem modificar de maneira significativa a morfologia geral do suporte, ou seja, não há façonagem. Essa categoria de instrumento costuma ser a mais comum nas indústrias líticas brasileiras, acompanhando sistematicamente indústrias mais elaboradas.
} 
esquerda do rio Verde e em seus afluentes, na forma de seixos. Podem ser também encontrados no topo dos abrigos. Os cristais de quartzo são observados dentro do basalto, são raros e de pequenas dimensões. Os óxidos de ferro também provém do basalto ou, ainda, de concreções dentro do arenito (SCHMITZ et al., 2004)

Trata-se de um arenito com alto grau de silicificação, homogêneo, granulometria fina a média, de coloração clara, caramelada e esbranquiçada, com córtex espesso presentes nos blocos retirados ou desprendidos naturalmente das paredes. Originariamente, os arenitos da Formação Botucatu tiveram contato com as lavas basálticas da Formação Serra Geral, formando localmente arenitos fortemente silicificados em camadas horizontais, espessas, em forma de mesas, torres, etc. (SCHMITZ et al., 2004). Mesmo que neste estudo não tenham sido realizadas lâminas delgadas para relacionar os instrumentos às fontes de matérias-primas, os grandes núcleos abandonados nos platôs, próximos às torres; os vestígios de exploração das paredes do abrigo (negativos de retiradas); as descrições das rochas, feitas a olho nu; além da grande quantidade de material lítico pesado e de grandes dimensões, não deixam dúvida de que se trata de uma matéria-prima local. A presença de uma matéria-prima local abundante e de excelente qualidade para o lascamento, implica em um baixo gasto de energia na busca da mesma e na não necessidade de estocagem no sítio. Por outro lado, a dimensão e qualidades excepcionais da jazida dão ao local uma significação distinta na composição do espaço tradicional. Os grupos passados certamente tinham o setor como um lugar de grande importância dentro de seus conhecimentos e o mesmo deve ter sido frequentado regularmente por seus atributos de ordem física, cultural e/ou simbólica.

A grande quantidade e a especificidade de material exumado do pequeno setor escavado denotam uma constante utilização do local ao longo de milhares de anos como um lugar de produção de instrumentos. Nesse sentido, é importante pensar que não se trata de uma amostra sistemática de uma ou duas cadeias operatórias, mas de porções de diversas cadeias operatórias que, muito provavelmente, se complementavam em outros locais do sítio, como aponta a ausência de certas fases de início de debitagem (não há lascas de entame $e^{3}$, por exemplo) ou dos instrumentos finais desejados. De uma maneira geral, a coleção apresenta grande parte dos processos de produção (SCHMITZ et al., 2004: 32): pequenos, médios, "grandes e até maiores que os grandes" núcleos (466 peças 0,57\%); lascas muito pequenas, pequenas (23.909), médias, grandes e "maiores que as grandes" (67.994 lascas, 83,57\%); fragmentos de dimensões e morfologias variadas (12.597 - 15,48\%); seixos (6 peças - 0,007\%); instrumentos unifaciais e bifaciais elaborados ou simples (entre outros: 1 instrumento bifacial grande; 19 pontas; 4 pontas de projetil), 94 unifaciais, percutores, etc., (290 instrumentos, 0,35\%).

O material depositado no Instituto Anchietano se divide entre grandes e médias lascas corticais ou semi-corticais de início de debitagem (entretanto não observamos lascas de entame, o que pode indicar que as mesmas ficaram no local de extração) e milhares de pequenas lascas de façonagem e de retoque de instrumentos unifaciais e bifaciais, realizados principalmente em arenito silicificado. As peças apontam para um excelente controle do lascamento e um alto nível de conhecimento dos lascadores, tanto da qualidade da matéria-prima utilizada, que responde muito bem ao lascamento, quanto da busca de suportes e instrumentos muito específicos, que são imagens mentais claras que obrigam os lascadores a se valerem sempre ou frequentemente das mesmas fases de produção, gerando, em consequência, uma grande quantidade de lascas normatizadas.

\footnotetext{
${ }^{3}$ Lasca de entame: também chamada de lasca inicial. Teoricamente é a primeira lasca retirada de um bloco de matériaprima (INIZAN et al., 2017) e apresenta sempre córtex, neocórtex ou faceta, no caso do cristal, em toda a na face superior e no talão.
} 
Mesmo se muitos instrumentos inteiros e fragmentados, unifaciais e bifaciais foram exumados durante as escavações, somente quatro dessas peças fazem parte desse estudo: um grande instrumento bifacial e três instrumentos unifaciais plano-convexos mais ou menos espessos, realizados sobre lascas alongadas, mais e menos largas. Por outro lado, dois outros instrumentos presentes nas coleções do Instituto Anchietano, provenientes de um sítio próximo (por volta de 6,0 km), GO-JA-14, fazem parte desta análise em função de seu nível de elaboração, pois certamente complementam a intenção da produção da região. Trata-se de instrumentos provenientes dos níveis antigos do sítio, datados de $10.740 \pm 85$ B.P. (Cal B.P. 12.838 a 12.397). De acordo com Schmitz e colegas (2004), esse sítio, como o GO-JA-03, apresenta uma estratigrafia profunda, constituída por treze camadas, sendo a única datação proveniente da camada 12 (fig. 2).

O ideal seria, após o estudo, inserir os conjuntos analisados dentro do contexto do sítio, aproximando-os do restante das coleções exumadas, realizando remontagens físicas, buscando as repartições espaciais ao longo dos diferentes momentos da cronologia, ou, ainda, apresentar estudos relacionados aos macro e micro traços de possíveis utilizações, procurando interações funcionais entre os diferentes setores e também relacioná-los a outras matérias-primas. Entretanto o estudo ficou limitado ao setor aqui apresentado, a uma caracterização geral das séries líticas analisadas, a uma descrição e reflexão sobre a intenção das produções, da transformação do material bruto em diferentes instrumentos ao longo dos períodos antigos. Ainda, os dados apresentados por outros autores serão integrados aos nossos resultados.

\section{AS INFORMAÇÕES TECNOLÓGICAS DAS SÉRIES ESTUDADAS}

\section{As cadeias operatórias}

A leitura tecnológica dos diferentes tipos de vestígios permite buscar a intenção da produção, como podem se organizar e se estruturar as fases de produção dos objetos, como os restos técnicos se conectam. Por outro lado, a ideia atual, em muito baseada em estudos etnoarqueológicos, é que as ações técnicas são construções culturais as quais foram, em um primeiro momento, estabilizadas e memorizadas para, em seguida, serem transmitidas tradicionalmente dentro do grupo. Os objetos são imagens mentais mais ou menos racionais, nesse sentido, todo ato técnico é carregado de intenções culturais, pois traz em si uma relação estrita com os conhecimentos apreendidos, memorizados e transmitidos através das gerações. Cabe ao tecnólogo buscar evidenciá-los e para isso é fundamental identificar as preferências, os conhecimentos, as performances (PELEGRIN, 2000). Assim organizado, o estudo permite discutir a função dos diferentes sítios e ainda tentar delimitar o nível econômico dentro do quadro local ou regional.

O interesse dessa análise é apreender e evidenciar as tendências, os gestos, as técnicas e os métodos das etapas das diferentes cadeias operatórias das indústrias líticas exumadas, buscando, mais do que os objetos, as intenções humanas.

No material estudado foi possível observar duas cadeias operatórias principais, mais elaboradas, e uma terceira, mais simples, realizadas sobre distintos restos brutos de debitagem. Uma quarta cadeia operatória foi observada sobre os instrumentos provenientes dos níveis antigos do GO-JA-14 (fig. 3): 
Figura 3 - As diferentes intenções produtivas: os instrumentos.

A: Unifacial C7, nível 31 - o suporte é uma lasca alongada (19 x6,2 x 1,8 cm), façonada unifacialmente, retirada por percussão tangencial de pedra macia, talão pequeno liso, abrasado, sem acidentes $(19 \times 6,2 \times 1,8 \mathrm{~cm})$. B: Unifacial no. 531, C4, nível 18 - unifacial sobre lasca alongada $(16 \times 3,9 \times 1,8 \mathrm{~cm})$, retirada por percussão tangencial de pedra macia, face inferior quase plana e talão diminuto; façonada nas laterais com duas séries de retiradas, por vezes, refletidas. Apresenta estigmas de (provável) encabamento (embotamento e micro estilhaçamento) na porção meso proximal. C: Unifacial no. 680, C4, nível 18 - unifacial sobre

lasca alongada $(12,2 \times 3,7 \times 1,2 \mathrm{~cm})$ pouco espessa na parte proximal $(0,7 \mathrm{~cm})$ e mais espessa na parte distal $(1,4 \mathrm{~cm} ; 1 \mathrm{~cm}$ na parte central). D: Unifacial no. 513, GO-JA-14, desmoronamento de níveis antigos - instrumento sobre lasca alongada, muito pouco espessa $(10,2 \times 3,1 \times 0,5 \mathrm{~cm})$, retirada por percussão macia orgânica, pequeno talão; apresenta uma retirada central que se assemelha a uma canelura, rodeada por pequenas retiradas que criam um gume equilibrado. E: Bifacial no.533, CVII, nível 20 - instrumento bifacial, sobre lasca mais larga do que longa $(9,2 \times 13,1 \times 2,3 \mathrm{~cm})$, retirada por percussão direta dura, retiradas bifaciais em maior número na face superior. F: instrumento simples, sobre lasca, com retoque unifacial.
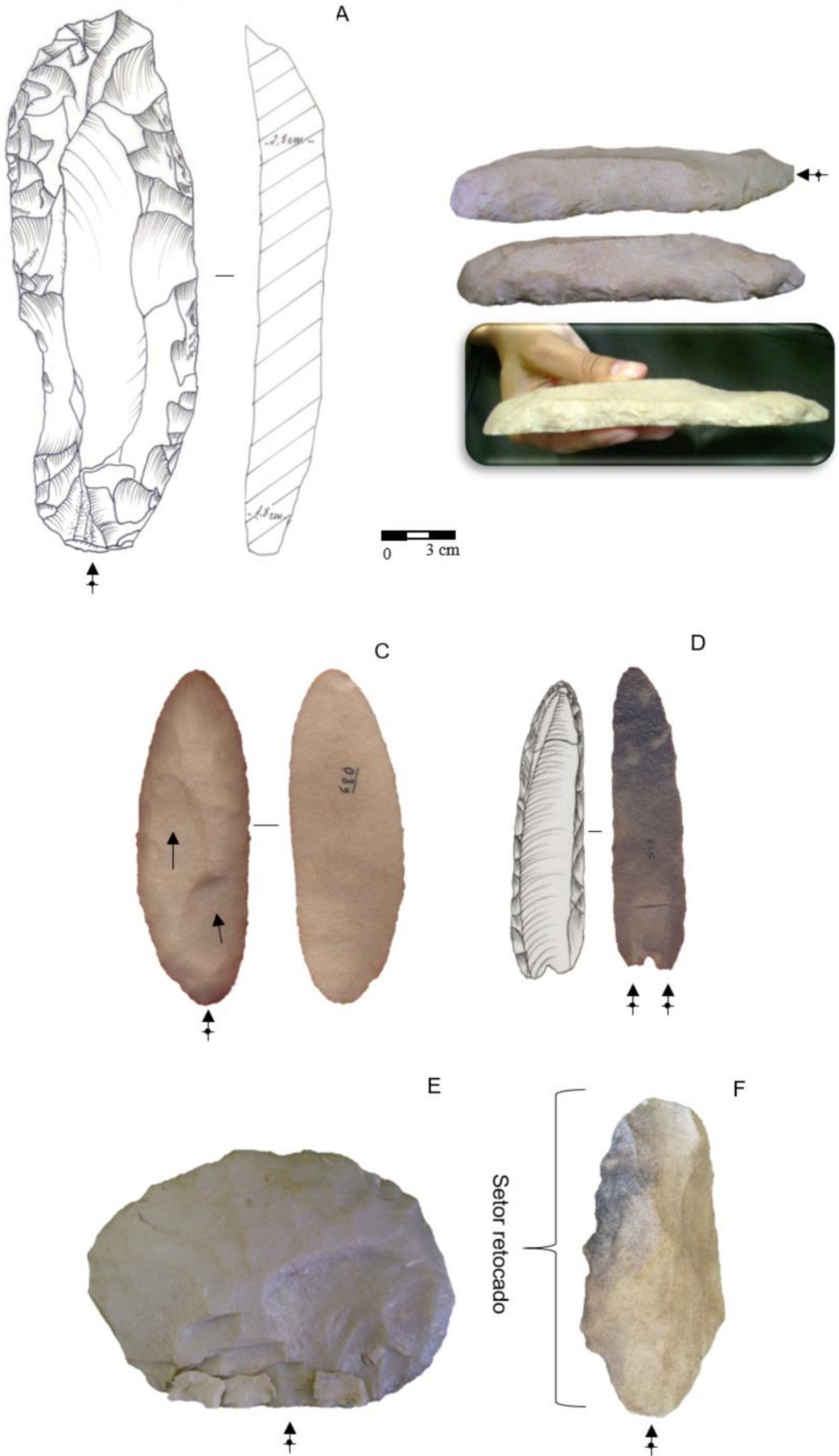
I. A primeira delas refere-se à produção de unifaciais sobre grandes lascas alongadas, mais ou menos espessas, largas, retiradas por percussão direta dura ou percussão tangencial de pedra macia. Os suportes procurados terão sistematicamente talões pequenos (em relação às dimensões da lasca), sem bulbo marcado, setor proximal pouco espesso em oposição a uma parte distal mais espessa, faces inferiores tendendo a planas, sem acidentes acentuados. Os talões são preparados por procedimentos específicos que os evidencia, seja por abrasão insistente, por émoussé ou por pequenas retiradas no entorno de onde será dado o golpe. Nas faces superiores, os maiores negativos centrais, geralmente realizados antes da retirada do suporte, podem ser no mesmo sentido da lasca suporte, com um pequeno deslocamento do eixo de percussão ou, menos frequente, podem apresentar retiradas ortogonais ao eixo de debitagem. Os instrumentos analisados, assim como as grandes lascas alongadas da coleção, apresentam duas ou mais retiradas centrais (nem sempre na mesma direção do suporte) anteriores à debitagem da lasca;

II. A segunda cadeia operatória, menos visível na coleção (em função de uma menor quantidade de estigmas relacionados à produção bifacial, tais como, talões diedros, faces superiores com negativos opostos, etc.), produz peças bifaciais. Esse conjunto pode ser dividido em produções distintas: na primeira encontra-se um grande instrumento bifacial sobre lasca mais larga do que longa, com pouca transformação, além das pequenas lascas de retoque com estigmas típicos de percussão bifacial. Na segunda, aparecem os restos brutos de lascamento de pontas de projétil bifaciais. Trata-se uma grande quantidade de pequenas e médias lascas de façonagem e de retoque, pouco espessas com talões lisos, lineares, em asa ou diedros, abrasados insistentemente e/ou com émoussé, retiradas por percussão direta macia orgânica ou dura. Nas faces superiores, há negativos na mesma direção do suporte, além de outros com pouco ou maior deslocamento de eixo ou em oposição ao eixo da lasca. As faces inferiores não apresentam bulbos ou acidentes marcados, os perfis tendem a retos ou curvos;

III. A terceira produção, simples, é realizada sobre qualquer categoria de restos brutos da debitagem. A presença de 22 instrumentos pouco transformados, simples, unifaciais, confirmam essa intenção. Trata-se de lascas (ou fragmentos) de dimensões variadas (grandes, médias ou pequenas), sem padronização, com ou sem córtex. Os retoques unifaciais, mais raramente bifaciais, ocupam pequenas partes dos gumes, sem, no entanto, transformá-los muito;

IV. Ainda, acrescenta-se à análise uma quarta produção proveniente do sítio GOJA-14: trata-se de instrumentos unifaciais pouco espessos bastante padronizados, sobre suporte alongado, retirados por percussão macia. A face superior apresenta uma grande retirada na mesma direção do suporte, lembrando uma canelura. A face inferior é plana, sem acidentes. Trata-se de instrumentos alongados com gumes cortantes.

\section{As intenções das produções}

Um objeto é uma imagem mental pré-definida culturalmente, mais ou menos racional, à qual, na ausência do modelo, o lascador se remete (PELEGRIN, 1986 [1995]). Nessa perspectiva, os instrumentos líticos mais elaborados são imagens dos pensamentos e dos desejos sociais e têm com eles uma relação "dialética": tanto estruturam a sociedade como são estruturados por ela. Estruturam no sentido que são necessários certos conhecimentos tanto do espaço de vivência, para, por exemplo, encontrar certas matérias-primas de qualidade, quanto no savoir-faire para trabalhá-las. Nem todos em um grupo podem ou estão aptos a caminhar muitos quilômetros na busca de rochas ou dominam as diversas técnicas de lascamento. Entretanto, certamente, parte dos membros de um grupo tem um mapping do espaço na mente e conhecem os locais importantes que 
dispõem das matérias-primas fundamentais para a (sobre)vivência da comunidade. Havendo uma matéria-prima de qualidade para o lascamento, o grupo se organizará para explorá-la em um determinado período do ano ou quando houver necessidade. Ademais, certamente existe um grupo específico que se dedica e domina as regras do lascamento. Podemos imaginar lascadores em diversos estágios de aprendizado no entorno de um lascador experiente (fato observável também no material arqueológico - CHAUCHAUT \& PELEGRIN, 2004; RODET \& DUARTE-TALIM, 2013; DUARTE-TALIM \& RODET, no prelo; KLARIC, 2018; por exemplo). Em contrapartida, os objetos produzidos pela sociedade são representações e desejos de seus membros e contém em si tais aspectos. Quanto mais estruturados, mais racionais eles são, mais representativos do arcabouço social, mais normatizados, o que permite ao tecnólogo observar com uma certa facilidade as regras que o gerenciam.

No caso da coleção analisada do sítio GO-JA-03, as principais cadeias operatórias presentes ao longo da estratigrafia mostram a procura por pelo menos três objetos específicos. O principal deles, que parece se perpetuar por um tempo longo na região e sobre os quais temos um maior número de informações tecnológicas, são os unifaciais alongados de seção plano-convexa, realizados sobre lascas de arenito silicificado ou de quartzito, normatizadas, retiradas por percussão direta dura ou por percussão tangencial de pedra macia. A segunda principal intenção seria a produção de pontas de projétil bifaciais, e uma terceira intenção, menos presente nos restos brutos de lascamento, é a produção dos grandes bifaciais. Em uma análise um pouco mais ampla do setor do sítio, podemos conectar ainda os grandes unifaciais alongados, retirados por percussão macia orgânica tangencial, muito pouco espessos, que apresentam um negativo na face superior como uma canelura, provenientes do sítio GO-JA-14.

Os unifaciais de secção plano-convexa (fig. 3) são produzidos a partir das grandes lascas alongadas, espessas na parte distal, com pequenos talões, sem bulbos marcados. Esses suportes bem normatizados parecem ser a base dos instrumentos os quais seguem essa mesma morfologia, em todo caso, no início de sua produção. Do nosso ponto de vista, trata-se de um tipo de instrumento que, ao longo de sua existência, evolui em sua morfologia (entre outros aspectos, através de sua utilização, redução, transformação, reconfiguração de sua morfologia e mesmo em função dos diferentes níveis dos lascadores que podem trabalhá-lo ao longo de sua existência). No primeiro momento de sua produção, os instrumentos podem medir mais que $20 \mathrm{~cm}$ de comprimento. Uma regra clara pôde ser observada, presente sistematicamente nas grandes lascas: a parte proximal mais estreita e pouco espessa se opõe a uma parte distal espessa e larga. Algumas retiradas centrais, frequentemente anteriores à debitagem do suporte, por vezes largas, estruturam a face superior da lasca. $\mathrm{O}$ trabalho de façonagem, por sua vez, contorna quase toda a peça (salvo, frequentemente, o setor do pequeno talão), com séries de retiradas pouco espessas, que partem da face inferior e terminam nesses grandes negativos centrais, produzindo dorsos mais e menos abruptos e segmentos de gumes retilíneos, convexos ou côncavos. Os dois gumes laterais paralelos estão ligados por um terceiro, arredondado (parte distal do suporte) que tem um tratamento diferenciado, com negativos mais longos e curvos, por vezes, criando um denticulado no gume. O interesse nesse primeiro momento é manter a cintragem desse setor. $\mathrm{O}$ objeto final é equilibrado e apresenta uma grande extensão de gume (laterais e distal) que, somados, inicialmente, podem chegar a mais de $20 \mathrm{~cm}$. Todo o trabalho de façonagem é realizado ora por percussão orgânica, ora por percussão direta dura. Entre as ações técnicas, tais como preparar o talão com pequenas retiradas laterais (provavelmente por percussão tangencial de pedra macia), abrasar, émoussé e retirar a lasca, existe um ir e vir intenso, o que significa uma troca de técnica frequente durante essa fase da produção. 
A outra intenção clara é a produção de pontas de projétil, materializada nas lascas de façonagem e de retoque com talões e estigmas característicos (talões diedros, face inferior muito plana, principalmente no setor mesial, negativos opostos na face superior...). Por outro lado, a produção bifacial parece mais ampla, como indica o grande instrumento com retoque bifacial realizado sobre lasca mais larga do que longa (fig. 3): apresenta retiradas extensas em alguns setores, diretas, inversas, alternadas e alternantes.

Finalmente, os instrumentos muito pouco espessos, alongados (fig. 3), representados por dois exemplares do sítio GO-JA-14, indicam e complementam as intenções e capacidades técnicas de produção destas populações antigas. Trata-se de instrumentos muito pouco espessos (com espessuras que variam entre 0,5 $\mathrm{cm}$ e 0,6 cm nos gumes laterais e $0,3 \mathrm{~cm}$ na canelura central) sobre grandes lascas. As lascas suporte muito padronizadas apresentam talões muito pequenos em relação às dimensões da lasca. Suportes alongados, com espessura mínima e talões de pequenas dimensões só podem ser resultantes da percussão macia orgânica.

\section{Os instrumentos unifaciais}

Diante dos instrumentos unifaciais de seção plano-convexa, o projeto do lascador parece bem identificado. A morfologia alongada com extremidades opostas, uma extremidade mais espessa do que a outra e com tratamentos diferenciados, além de uma face plana e outra convexa, parece ser uma escolha cultural bem específica e uma imagem mental estabelecida. Normas estritas influenciam não só nas dimensões e morfologias, mas também na criação de ampla disponibilidade de gumes. A partir de uma grande lasca alongada e larga, com um ou mais negativos centrais, retira-se pequenas quantidades de matéria-prima no seu entorno a partir da face inferior, criando um volume inicial alongado com gumes paralelos, mais e menos retilíneos, por vezes, ligeiramente convexos, e outro tendendo a ogival na sua parte mais espessa (porção distal da lasca suporte). Esses instrumentos guardam em si suas próprias reservas de matéria-prima e, muito provavelmente, são objetos de utilização variada e uso longo, podendo ser transformados morfologicamente, como indicam os vários estados técnicos nos quais são encontrados (inicial, já utilizado e pouco reavivado ou, ao contrário, muito reavivado e morfologicamente diferente do seu aspecto inicial). Esses variados estados técnicos podem ser interpretados como instrumentos distintos. A questão que pode ser colocada é: um objeto em transformação morfológica (e talvez funcional) ao longo de sua vida deve ser apreendido sempre como sendo o mesmo instrumento ou, de fato, trata-se de vários instrumentos que correspondem a intenções de produção distintas? Um primeiro nível de reflexão seria pensar que essas diferentes morfologias e funcionalidades já estão introspectadas no projeto mental inicial, ou seja, as possíveis transformações do objeto já estariam previstas desde sua concepção (RODET, 2006; LOURDEAU, 2010). Outro elemento importante que ajuda a refletir sobre esses unifaciais plano-convexos é pensar que um instrumento pode ter funções diferentes de acordo com as morfologias, volumetrias, ângulos e tipos de gumes (LOURDEAU, 2010; 2016), mas também certamente em função do tipo de superfície na qual ele vai agir. Um único instrumento pode agir sobre distintas superfícies para raspar, furar, cortar, etc.; nesse sentido, ele terá diferentes tipos de ângulos e gumes e isso pode estar previsto desde o momento de sua concepção.

Os unifaciais de secção plano-convexa são instrumentos estabilizados presentes em várias regiões do Brasil e da América do Sul desde a passagem dos períodos Pleistoceno e Holoceno e no início do Holoceno.

Em uma escala geográfica mais ampla, a presença de instrumento unifaciais coexistindo com outros, bifaciais, tem sido observada em ocupações antigas de sítios do 
Chile, do Peru, da Venezuela e da Colômbia (DILLEHAY, 1999; DILLEHAY et al., 2015). No Chile, no Altiplano do Deserto do Atacama (3.000 m e $4.500 \mathrm{~m}$ de altitude), foram encontrados diversos sítios com datas antigas (11.490 cal BP para o mais antigo $)^{4}$, dos quais foram exumados, entre outros, instrumentos unifaciais de seção plano-convexa elaborados, normatizados e de vida longa, sobre rochas de excelente qualidade para o lascamento (SANTORO \& CHACAMA, 1984; OSORIO et al., 2011, 2017 - fig.4).

No extremo sul do Peru, também em um contexto de Altiplano, o abrigo do Caru, datado de $8.190 \pm 130 \mathrm{BP}$ (Cal BP 9.528-8.584 anos), apresenta indústrias bifaciais e unifaciais. Os unifaciais são realizados sobre lascas de jaspe, microdioritas, cherts, basaltos, etc., provenientes dos seixos locais, classificados como raspadores discoides e laterais (RAVINES, 1967, 1972). Ainda no Peru, na área desértica de Cuspinique, encontra-se os sítios com as pontas Paijan e sua cadeia operatória de produção, juntamente com unifaciais, datados entre $8.730 \pm 160$ BP (Cal BP 10.298-9.131 anos) até $10.380 \pm 170$ BP (Cal BP 12.707-11.274 anos), para o sítio Pampa de los Fossiles 14 (CHAUCHAT et al., 2016), por exemplo. Esses são realizados sobre tufa vulcânica e façonados por percussão macia orgânica (CHAUCHAT \& PELEGRIN, 2004; entre outros - fig. 4).

Figura 4 - Pontas bifaciais e peças unifaciais de sítios da América do Sul. A: Indústria Paijan, do Peru. Acima, pontas Paijan estreitas e mais largas. Abaixo, unifaciais, com secção plano-convexa. Adaptado de CHAUCHAT (1991). B: Indústria do sítio Las Cuevas, do Chile. Acima, tem-se exemplos das pontas de projétil bifaciais. Abaixo, instrumentos unifaciais, mais ou menos espessos, com secção plano-convexa. Adaptado de Santoro e Chacama (1984).

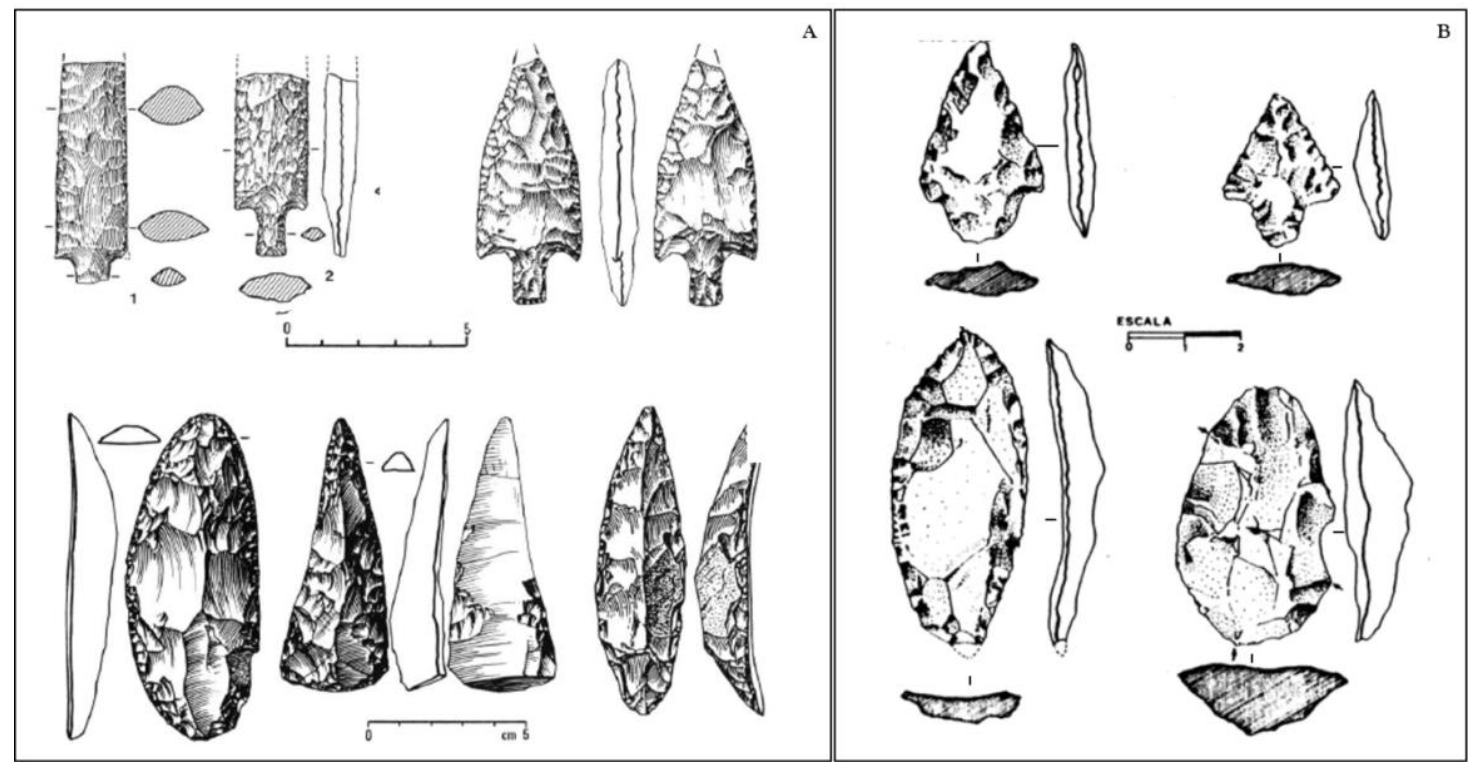

No Brasil, os instrumentos de seção plano-convexa estão presentes em vários locais. Entretanto, na região de Serranópolis, estado de Goiás, a presença desse tipo de instrumento é sistemática e a produção dos unifaciais parece ter um papel central nas indústrias líticas.

\footnotetext{
${ }^{4}$ Outros sítios do altiplano do Deserto do Atacama com esse mesmo contexto podem ser citados: Las Cuevas (11.490 cal BP e 10.865 cal BP); Hakenasa (11.427 cal BP), Patapatame (8.160 340 BP - Cal BP 10.299 -7.970 anos); Ipilla 2 (9.6709541 cal BP - SANTORO e CHACAMA, 1984; OSORIO et al., 2011, 2017).
} 
$\mathrm{Na}$ coleção estudada, dois exemplares analisados provêm da área em estudo, como já dito, possivelmente um setor de produção lítica, o terceiro vem do corte próximo (CVII - fig. 2). Assim, podem não ser o objeto procurado, ou seja, a intenção final do lascador, mas algo que não deu certo e foi abandonado ou o reflexo de um aprendiz ou de um lascador pouco experiente. $O$ objeto desejado certamente não ficou no setor de lascamento, foi levado para outro local onde foi consumido. No entanto, mesmo nesta perspectiva, os instrumentos que ficaram no local da produção contêm em si, pelo menos, parte das normas que o grupo estabeleceu:

\section{As informações tecnológicas dos restos brutos de lascamento}

Algumas características tecnológicas são marcantes na coleção. A primeira delas é a abrasão insistente da área do futuro talão complementada por um émoussé intenso, que resulta em uma pequena superfície arredondada, polida, entre o plano de percussão e a superfície de debitagem, local que receberá a percussão. A segunda, em parte consequência da anterior, é a ausência ou a raridade de acidentes ao longo de todas as cadeias operatórias. Uma terceira particularidade pode ser vinculada a essas: trata-se das pequenas retiradas no entorno ou nas laterais do local da futura percussão, colocando-o em evidência e facilitando o lascamento. Essas preparações e seus resultados são muito específicos e apontam para um excelente controle da debitagem, um conhecimento da matéria-prima e um alto nível de savoir-faire, indicando a presença de lascadores experientes no local. A abrasão intensa permite recuar o ponto de impacto, entrando na massa do núcleo, resultando em talão e setor proximal pouco espessos. Abrasão e émoussé juntos correspondem à criação de um ponto de impacto "perfeito" para receber o choque da percussão e facilitar a inicialização da fratura. A área assim preparada não apresenta nenhuma asperidade na qual o percutor poderia esbarrar e desviar parte da força aplicada. Em consequência, estando o percutor em bom estado e sendo a matéria-prima homogênea, de boa qualidade para o lascamento, a fratura vai se inicializar e a onda de choque correrá livremente até a distância desejada pelo lascador, implicando em lascas totalmente sem acidentes e alongadas.

Um último elemento merece ser apresentado, refere-se às dimensões dos talões em relação ao tamanho das lascas. Trata-se de talões lisos ou lineares, pequenos $(1,2 \times 0,3$ $\mathrm{cm} ; 0,2 \times 1,7 \mathrm{~cm} ; 0,6 \times 0,4 \mathrm{~cm}$; etc.), em suportes que são sistematicamente mais longos do que $12 \mathrm{~cm}$. Esses elementos apontam para a utilização da percussão orgânica ou de pedra macia, com um golpe tangencial. Diante de pequenos talões, meticulosamente preparados, como é o caso na coleção, somente percutores macios e pesados ou de pedra macia, utilizados com gesto específico, são capazes de não fragmentar o bordo do núcleo, absorver parte do golpe e criar lascas longas, regulares, planas nas faces inferiores e pouco espessas no setor proximal. Por outro lado, a pequena dimensão dos talões permite concentrar a energia e inicializar a fratura concoidal, que, ao contrário, seria dispersada em talões maiores.

De acordo com M. Newcomer (1976), quando o tecnólogo entende os objetivos presentes nos restos brutos de lascamento, torna-se possível recolocá-los nos seus devidos lugares dentro das cadeias operatórias. Nesse sentido, algumas categorias de peças se mostraram mais diagnósticas tecnologicamente e permitiram compreender as principais intenções do lascamento. Trata-se: i. das grandes e médias lascas, alongadas ou largas, de início de debitagem, retiradas por percussão direta dura e percussão tangencial de pedra macia; ii. das grandes lascas suporte alongadas, retiradas por percussão tangencial de pedra macia, frequentemente com pequenos talões e iii. das pequenas lascas de façonagem e/ou retoque de instrumentos uni e bifaciais, retiradas por percussão direta dura e macia. 
As primeiras representam o início da debitagem sobre grandes núcleos (fig. 5): elas podem ser grandes e espessas, alongadas ou mais largas, corticais, sub-corticais ou, quando mais adiantado o processo do lascamento, sem a presença de córtex; retiradas por percussão direta dura ou por percussão de pedra macia, apresentando amplas dimensões $(13,8 \times 7,6 \times 3,5 \mathrm{~cm} ; 11,3 \times 6,2 \times 2,1 \mathrm{~cm} ; 22,7 \times 21,1 \times 4,9 \mathrm{~cm} ; 13,7 \times 21,3 \times 2$ $\mathrm{cm}$; etc.). Os talões, lisos, corticais ou mais raramente diedros, podem ser pequenos nas lascas mais longas ou mais largos e espessos nas lascas mais largas e compactas, preparados por abrasão ou pequenas retiradas ou, com menos frequência, sem nenhum tratamento. Nas faces superiores, os negativos podem vir da mesma direção da lasca, sendo incompletos, e indicam a exploração de grandes superfícies ou, ao contrário, podem vir de várias direções, apontando para distintos planos de percussão. Trata-se de peças frequentemente sem acidentes, raramente apresentam Siret ou refletido. Algumas dessas peças contêm cúpulas de contato térmico na face superior ou nas duas faces. Duas lascas da coleção apresentam um plano de percussão transitório, criado como estratégia para retiradas de preparação (J. Pelegrin, com. pessoal), mise en forme do núcleo (fig. 5). Outras lascas indicam a intenção do lascador em ter um controle, em calibrar o núcleo; em outras se nota claramente a preocupação em retirar os pequenos acidentes ou as arestas, limpando o núcleo de toda e qualquer inconveniência. De uma maneira geral, nota-se nessas lascas a intenção de criar amplas superfícies de debitagem sem acidentes, prontas para a retirada de grandes lascas suporte alongadas.

Figura 5 - Lascas de início de debitagem.

Trata-se de grandes lascas largas e compactas ou mais alongadas, retiradas por percussão direta dura ou pedra macia, com mais e menos córtex, com talões amplos e espessos ou pequenos. Em algumas delas, há cúpulas térmicas, indicando uma provável utilização do fogo em momentos anteriores (A). Algumas das lascas (B), nota-se lascas de limpeza e preparação de superfície de debitagem.
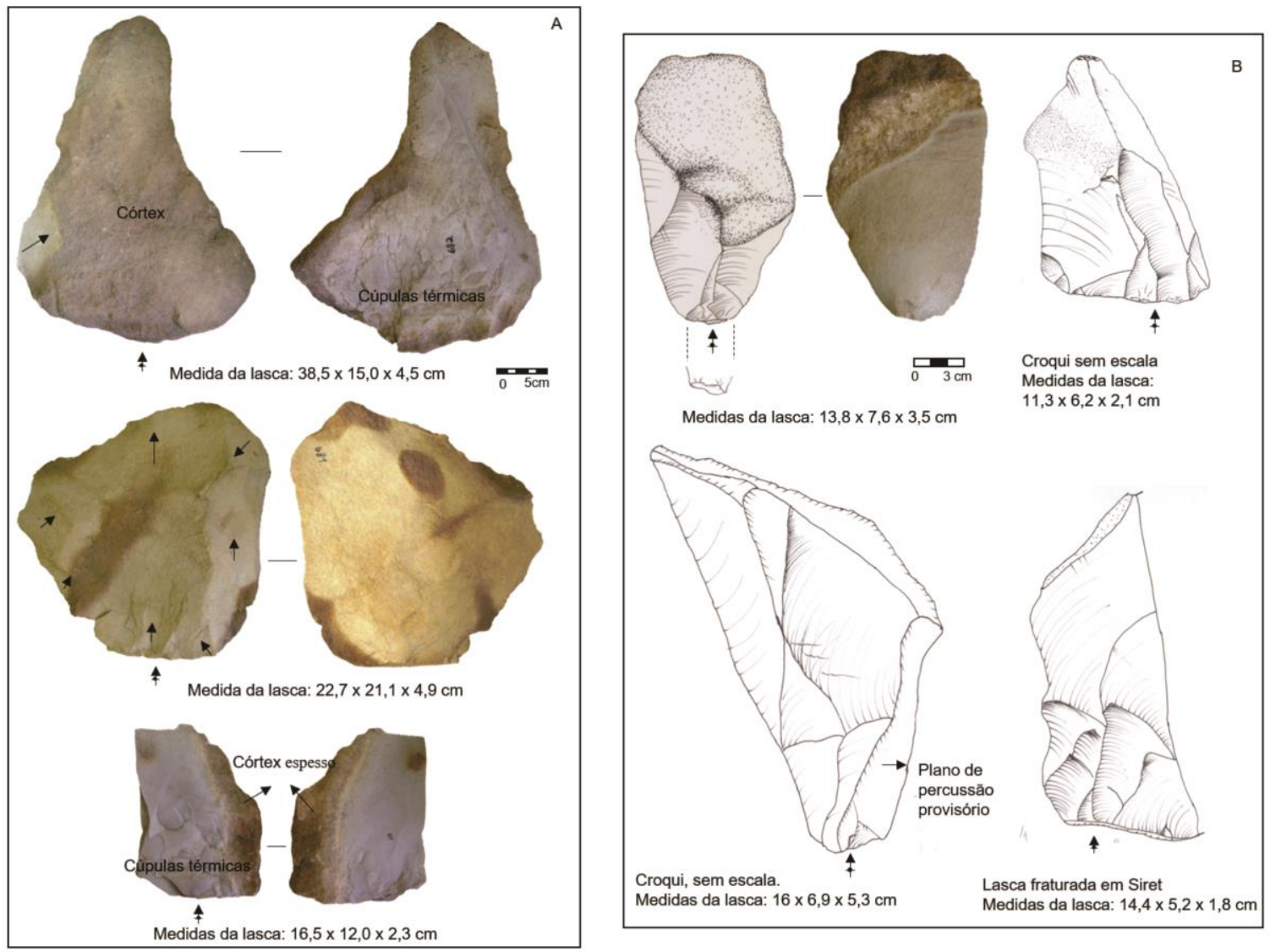
Por outro lado, as grandes lascas alongadas, largas, muito regulares, de plena debitagem, sem córtex ou neocórtex, são os mais próximos representantes dos produtos de primeira intenção, ou seja, os suportes dos objetos unifaciais plano-convexos (fig. 6). Essas lascas são retiradas por percussão direta dura e por percussão tangencial de pedra macia. As peças apresentam um tratamento sistemático do talão, colocando-o em evidência, facilitando, assim, a precisão do gesto da percussão (abrasão insistente e/ou émoussé, pequenas retiradas nas laterais do talão, etc.). Os resultados são produtos regulares, sem acidentes, bastante longos (na coleção podem chegar a mais de $20 \mathrm{~cm}$ de comprimento), pouco espessos na parte próxima ao talão (meso-proximal) e espessos no setor distal. Tal morfologia pode ter sido uma escolha cultural, entretanto, de acordo com J. Pelegrin (com. pess.), a utilização da percussão macia ou de pedra macia para retirar grandes lascas é muito eficaz, porém, necessita de talões muito abrasados, o que faz entrar na massa do núcleo gerando tecnicamente lascas pouco espessas no setor proximal. Ainda, o percutor macio demanda gestos tangenciais, que implicam em tocar superficialmente o plano de percussão, que deve ser minuciosamente preparado para suportar a pressão do percutor (um talão pequeno equivale a uma maior pressão, ainda que o peso do percutor seja o mesmo). Em consequência, as faces inferiores se apresentam livres de bulbos, tendendo a planas/achatadas. Nesse sentido, uma lasca alongada pouco espessa no setor proximal pode ser um resultado da técnica empregada, e não somente de uma escolha cultural da morfologia do instrumento. Finalmente, na face superior, as peças apresentam um ou mais negativos que tendem a ser na mesma direção do suporte ou ligeiramente fora do eixo, apontando para uma configuração sistemática do núcleo.

Ainda, vale acrescentar a esse grupo diagnóstico os suportes de grandes lascas alongadas do sítio GO-JA-14, muito padronizadas, retiradas por percussão macia orgânica, muito possivelmente com um percutor de madeira, pesado (J. Pelegrin, com. pessoal), ou por um grande e pesado chifre de um cervo-do-pantanal (Blastocerus dichotomus - animal que no passado era abundante desde o sul da Amazônia até o norte da Argentina - RAMOS, 2004). Trata-se de peças muito normatizadas (alongadas e muito pouco espessas) que requerem uma imagem mental pré-definida e um alto nível de savoir-faire.

Figura 6 - Lascas de plena debitagem, suporte dos instrumentos unifaciais. Trata-se de lascas retiradas por percussão tangencial de pedra macia, alongadas, chegando a $20 \mathrm{~cm}$, que têm talões pequenos, preparados através de abrasão e émoussé; o setor proximal é pouco espesso em oposição a uma parte distal mais espessa, e as faces inferiores tendem a ser a planas, com presença de esquilhamento do bulbo. Estas deixadas no local não apresentam as normas procuradas e por isso foram abandonadas (refletidos, quebras, pequena largura).

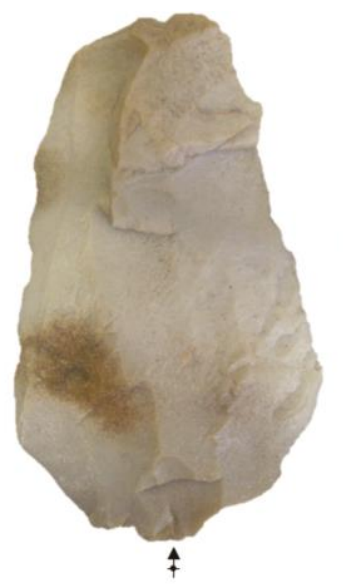

Medidas da lasca: $24,2 \times 12,1 \mathrm{~cm}$
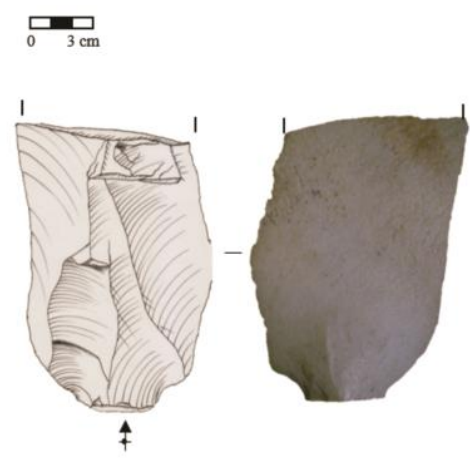

Medidas da lasca: $12 \times 9 \times 2 \mathrm{~cm}$

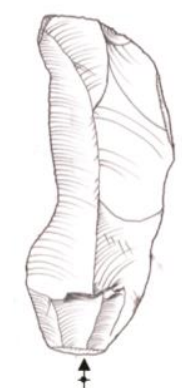

Medidas da lasca: $15,5 \times 4,8 \times 1,4 \mathrm{~cm}$ 
As lascas de façonagem entram na cadeia operatória de produção de dois tipos distintos de instrumentos, os unifaciais e os bifaciais (fig. 7). Para os primeiros, de uma maneira geral, essa categoria apresenta produtos muito normatizados, existindo pelo menos duas tendências de padrões morfológicos: morfologia quadrangular (próximos de $3 \times 3 \mathrm{~cm}, 4 \times 4 \mathrm{~cm}, 5 \times 5 \mathrm{~cm})$ ou mais alongada/retangular $(5,6$ ou $7 \times 3 \mathrm{~cm})$, pouco espessas $(0,4 \mathrm{~cm}$ e $0,3 \mathrm{~cm})$, retiradas por percussão direta macia orgânica ou direta dura. Os perfis são ligeiramente curvos ou abruptos, bulbos ausentes ou muito discretos. Um grupo bastante distinto dentro da categoria são as lascas com partes distais paralelas aos talões, o perfil tendendo a curvo, principalmente na parte distal. Trata-se de peças bem características da produção de instrumentos unifaciais que apresentam duas faces paralelas entre si. O paralelismo das duas extremidades permite medir inclusive a altura dos objetos (fig. 6). Na coleção observaram-se duas alturas preferencias de instrumentos: entre $2 \mathrm{~cm}$ e $3 \mathrm{~cm}$ e outra com pouco mais de $1 \mathrm{~cm}$.

A categoria apresenta talões lisos ou lineares, mais raramente em asa, pouco espessos. As preparações variam entre abrasão insistente combinada com éémoussé ou pequenas retiradas nas laterais do ponto de percussão, criando um talão em relevo, muito liso e resistente, que permite a inicialização da fratura sem nenhuma asperidade e sem refletidos. As faces superiores têm negativos que tendem a ser na mesma direção ou com um pequeno desvio do eixo. Os acidentes mais frequentes são as pequenas quebras laterais ou distais, provavelmente após o lascamento, dois pontos de impacto e a fissuração do talão em direção à face superior e/ou inferior, para os talões menos espessos. Algumas lascas apresentam córtex vestigial na parte distal, mais raramente na lateral ou no talão.

O segundo grupo, mais discreto, responde pela façonagem de instrumentos bifaciais e apresenta lascas alongadas (por volta de $4 \mathrm{~cm}, 5 \mathrm{~cm}$ e $6 \mathrm{~cm}$ para as maiores), pouco espessas $(0,2 \mathrm{~cm} ; 0,3 \mathrm{~cm}$ e $0,5 \mathrm{~cm}-$ fig. 7). Os talões, lisos ou, mais raramente, diedros, retirados por percussão direta macia orgânica, são pequenos $(0,5 \mathrm{~cm}, 0,7 \mathrm{~cm}, 0,9 \mathrm{~cm})$, muito preparados com pequenas retiradas ou abrasão e émoussé insistentes, o que coloca em destaque o local da percussão e permite um gesto preciso, sem erros ou acidentes. Os perfis podem ser inclinados, curvos ou rasantes. Por vezes, observa-se um setor plano na parte central em oposição a uma parte distal ligeiramente curva (este tipo de lasca é relacionado aos instrumentos bifaciais que apresentam superfícies planas). As faces superiores apresentam negativos na mesma direção, tangenciais ou, mais raramente, em oposição ao eixo da lasca. Os acidentes são raros e quando existem se resumem a um leve setor refletido no extremo distal da lasca (o que pode estar relacionado muito mais com uma superfície muito plana do que com um acidente), quebras laterais ou um talão fendido/dividido pela presença de uma fissura. Esses elementos indicam um lascamento controlado, ou seja, realizado por lascadores experientes.

Finalmente, um grupo de lascas de pequenas dimensões e pouco espessas $(0,9 \times 0,9$ x $0,1 \mathrm{~cm} ; 1,2 \times 1,1 \times 0,2 \mathrm{~cm}$ ou $1,4 \times 1,2 \times 0,1 \mathrm{~cm}-$ fig. 7 ) realizadas por percussão direta dura ou macia orgânica, apresenta talões lisos, lineares e, mais raramente, em asa, corticais ou diedros, sistematicamente abrasados e com émoussé, pôde ser relacionado ao retoque dos instrumentos unifaciais ou bifaciais. Os acidentes quando presentes são o refletido, a lingueta superior e a inferior, além das pequenas quebras distais ou laterais.

As outras lascas da coleção, menos normatizadas, estão muito próximas desses grupos, apresentando tecnologicamente as mesmas tendências, mas divergindo principalmente pela morfologia menos padronizada. 
Figura 7 - Lascas de façonagem e de retoque.

A: Lascas de façonagem de instrumentos unifaciais, retiradas por percussão direta dura ou macia orgânica, frequentemente com porção distal paralela ao talão e perfil curvo. B: Lascas de façonagem de instrumentos bifaciais, retiradas principalmente por percussão macia orgânica, pouco espessas, com negativos bidirecionais nas faces superiores, talões lisos ou diedros. C: Lascas de retoque, retiradas por percussão direta dura. D: Lascas de retoque, retiradas por percussão macia orgânica, com pequenas dimensões, talões diminutos, abrasados e/ou com émoussé.
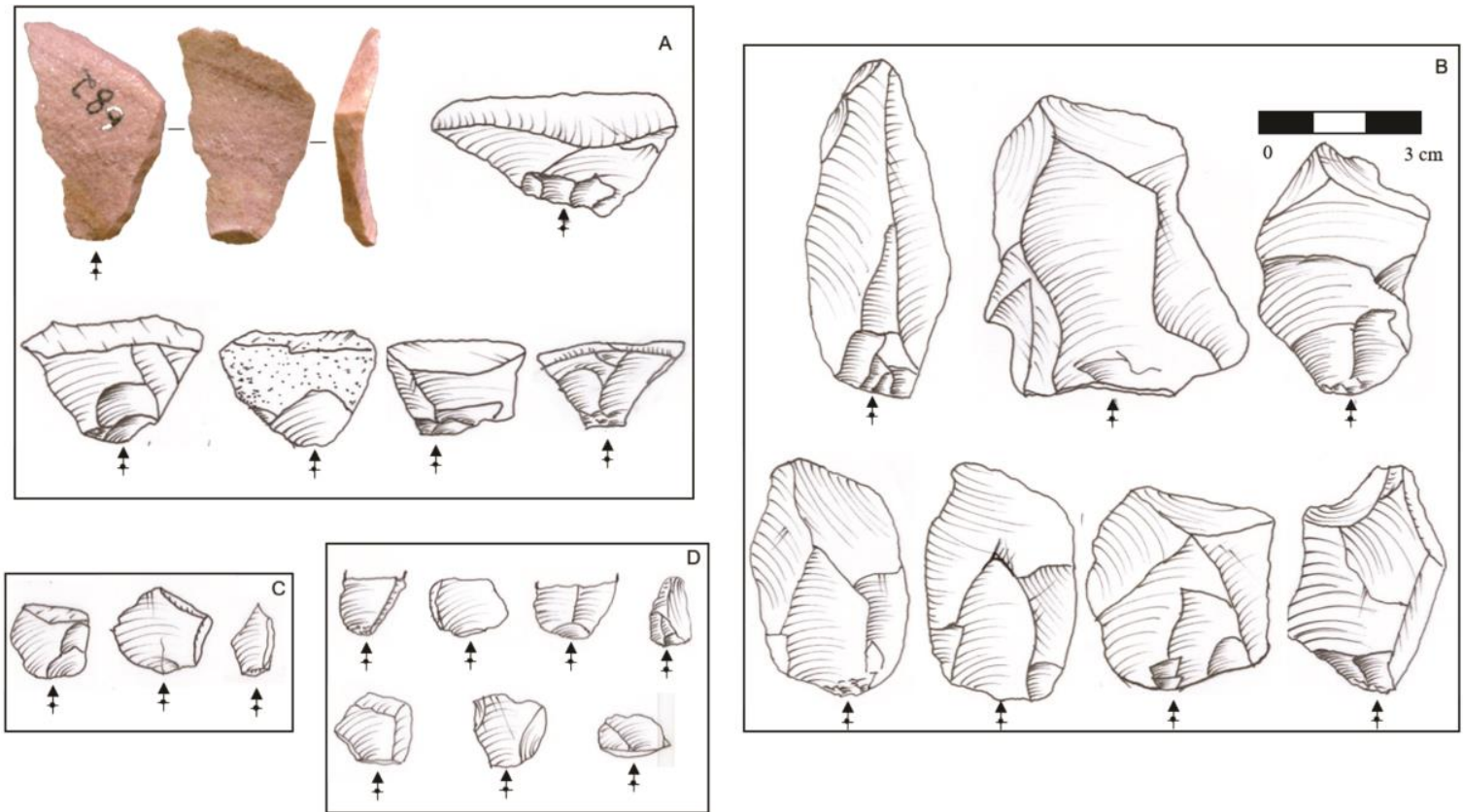

\section{Os acidentes de lascamento}

Com efeito, as indústrias líticas de Serranópolis estudadas apresentam um grande controle do lascamento. Os acidentes são raros e por vezes consequências da matériaprima, que, mesmo sendo de excepcional qualidade, pode não ter a silicificação adequada aos objetivos desta produção. Lembramos que não se trata de um sílex ou de um silexito, mas de um arenito muito silicificado. Ainda, a pouca espessura dos talões em relação ao peso do percutor e à força aplicada para retirar lascas de $15 \mathrm{~cm}$ ou até mais de $20 \mathrm{~cm}$ de comprimento, aliadas ao tipo de matéria-prima, são também os responsáveis pelos pequenos acidentes.

Um acidente recorrente observado principalmente na fase de façonagem são as fissuras presentes nos talões pouco espessos e que se desenvolvem a partir do talão em direção aos primeiros centímetros da peça, na face inferior ou superior, ou, ainda, nas duas faces ao mesmo tempo. Trata-se de um fissuramento que se alinha horizontalmente ao longo do comprimento do talão e que pode dividi-lo. Quando está presente na linha inferior do talão a fissura se dirige em direção ao bulbo, como um esquilhamento do bulbo, mas, frequentemente, sem destacar a esquilha; quando se materializa nas proximidades da linha superior do talão, se conduz em direção à face superior (fig.8). Ainda, o acidente pode fissurar o talão nos dois setores e criar esquilhas nas duas faces ao mesmo tempo. O esquilhamento do bulbo foi indicado por J. Pelegrin (2000) como um acidente relativamente específico e frequentemente ligado à percussão tangencial realizada por pedra macia, arenito, por exemplo. Entretanto, nesse caso específico, o acidente pode estar relacionado aos grãos da matéria-prima, que, mesmo tendo uma estrutura granulométrica silicificada, pode não ser totalmente compacta. Essa porosidade aumenta a possibilidade de fissuras, o que resulta em um esquilhamento do bulbo no momento do impacto (J. Pelegrin com. pess.) e no fissuramento do talão, seja 
em uma das faces ou nas duas. Por outro lado, a pequena dimensão dos talões e o peso do percutor acompanhado à pressão do golpe no talão, aliados aos elementos já descritos, podem também contribuir para esse tipo de acidente.

Figura 8 - O esquilhamento nas duas faces.

Um acidente recorrente é o esquilhamento do bulbo; pode também ocorrer que uma esquilha saia, ao mesmo tempo, na face superior da lasca (A), por vezes, fendendo o talão ao meio. Na figura $B$, a esquilha não se soltou totalmente, caso tivesse soltado o aspecto do talão seria de dois pontos de impacto, como mostra o pequeno croqui (B).

A

B
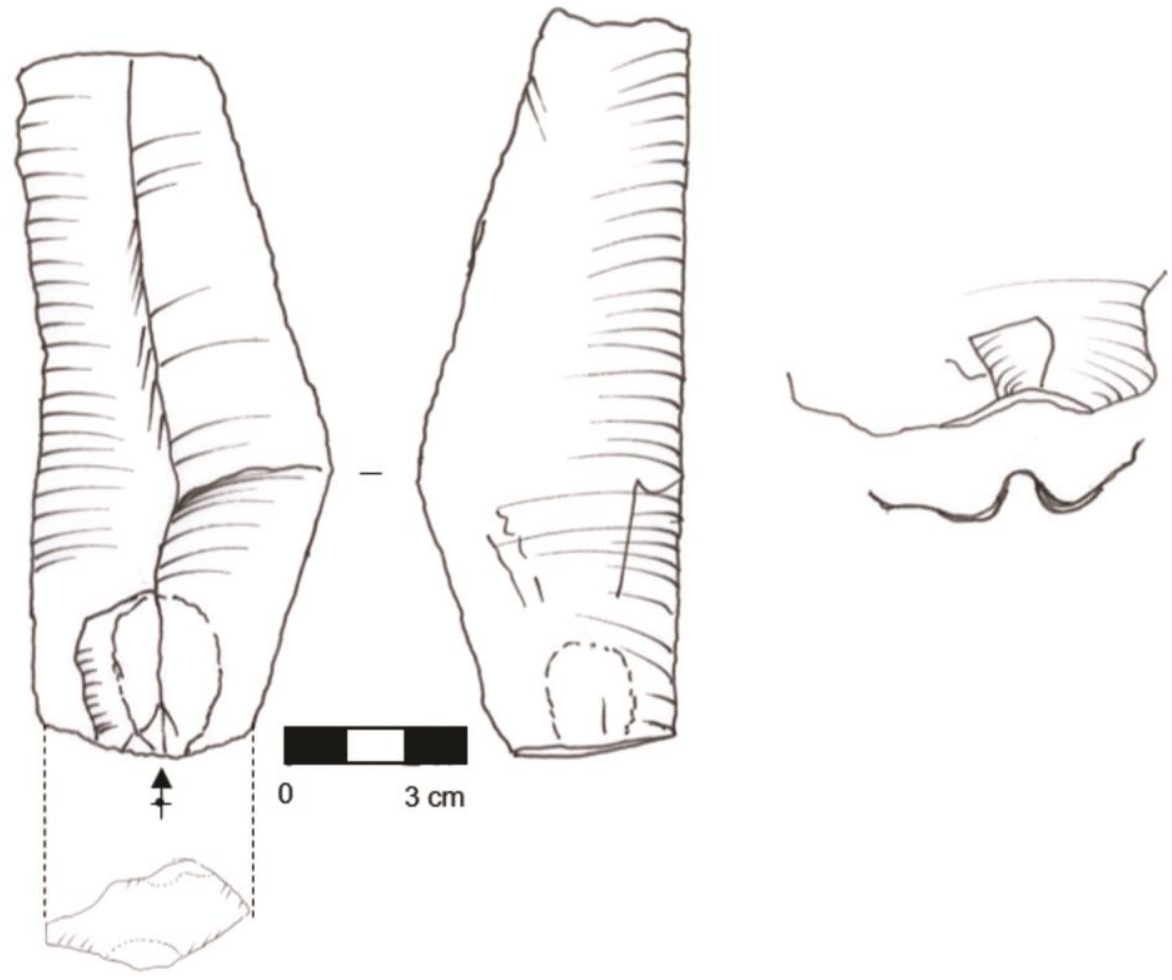

Uma variante desse acidente é a presença do que parece ser dois pontos de impacto que, de fato, é o resultado da saída da esquilha no meio do talão muito pouco espesso a partir do fissuramento. Essa pequena retirada deixa uma aparência final no talão de dois pontos de impacto (fig. 8).

Os outros acidentes, tais como refletido ou as linguetas, são muito discretos.

Enfim, de uma maneira geral, a indústria é pouco acidentada apontando para um excelente controle do lascamento.

\section{DISCUSSÃO TEÓRICO-METODOLÓGICA}

A abordagem tecno-econômica da Escola Francesa (MAUSS, 1947; MAGET, 1953; LEROI-GOURHAN, 1964; TIXIER, 1967, 1980 [1984]; PERLÈS, 1980; PELEGRIN, 1986 [1995]; BOËDA, 1990; PIGEOT, 1991; INIZAN et al., 2017; dentre outros) é um poderoso instrumento de análise e compreensão de conjuntos culturais, trata-se de conceitos universais e tem sido aplicada com sucesso aos estudos tecnológicos na Europa e em outros países, como é o caso inclusive dos estudos de coleções líticas brasileiras (FOGAÇA, 2001; DIAS, 2003; VIANA, 2005; RODET, 2006; BUENO, 2007; FAGUNDES, 2007; ISNARDIS, 2009; FERNANDES, 2011; DUARTE-TALIM, 2012; MACHADO, 2013; RODET et. al., 2013; DA COSTA, 2017; FERNANDES \& DUARTETALIM, 2017; dentre outros). A maneira como o pensamento teórico metodológico da 
Escola Francesa foi concebido e evoluiu ao longo dos últimos quarenta anos tem permitido, por um lado, caracterizar distintas produções e, por outro lado, compará-las tanto no tempo, quanto no espaço. Se, até o final dos anos 1960, as coleções líticas eram analisadas através de uma perspectiva tipológica, na qual o instrumento finalizado era o centro das atenções, e os processos produtivos não eram considerados, a partir dessa data, inspirados nos legados de correntes de pensamento provenientes da etnologia e da antropologia, os pré-historiadores franceses irão propor uma nova abordagem. Nesse momento, J. Tixier (1967) desenvolve duas noções muito importantes e distintas: método e técnica. Enquanto o método responde pelo gerenciamento sistemático da debitagem ou da façonagem de um instrumento, com a intenção de atingir um objetivo específico, a segunda vai definir o modo prático como a mesma foi realizada, a execução das retiradas ou de sequencias específicas (PELEGRIN, 2005). A Escola Francesa mergulha em novas problemáticas, se interessando pelos conhecimentos técnicos das sociedades passadas. A. Leroi-Gourhan (1945 [1973]) se inspira nas pesquisas de M. Mauss (1947) e M. Maget (1953) para criar uma análise paleoetnológica das sociedades passadas. Para M. Mauss (1947), a sociedade é um todo articulado, assim sendo, a realidade social poderia ser entendida a partir do estudo de suas partes constituintes, as quais possuem características e funções específicas. Um fenômeno deveria ser estudado em separado e, em seguida, inserido em sua totalidade articulada. A partir dessa ideia e inspirado no pensamento de M. Maget (1953), que busca compreender os processos técnicos que envolvem os Homens e os objetos, A. Leroi-Gourhan (1943 [1971]) procura entender o fenômeno da produção humana, mas o objeto não se resume em si mesmo, ao contrário, conduz a aportes para a reconstituição de uma sociedade passada. Diferentemente da tipologia, para a qual o objeto é estático, aqui ele está em movimento. Assim, o interesse passa a ser reconstituir as atividades técnicas desde a matéria-prima bruta até o abandono do utensilio, passando por todas as etapas de realização do instrumento, observando em cada uma delas as ações e os gestos técnicos. Trata-se de conhecer o papel da matériaprima em si mesma, mas principalmente em sua relação com os Homens para adentrar na realidade social e cultural. O interesse agora é abolir a separação entre técnica e fato social (LEROI-GOURHAN, 1964). Nessa perspectiva, outros aspectos da vida cotidiana passam a tomar parte das análises: o meio ambiente, os restos de produção, as distintas tecnologias presentes nos sítios arqueológicos, os instrumentos simples.... Enfim, nasce a noção de Cadeia Operatória.

Assim, dentro da busca das intenções humanas detrás dos objetos, em um primeiro momento, é necessário um estudo minucioso de cada uma das distintas fases de produção de um determinado instrumento (nem todas as fases estão presentes nas coleções): as intenções, os gestos, as técnicas, etc., que cada fase guarda em si, para em seguida reintegrar os dados em um corpo maior do processo de produção. Esse sistema permite entender onde estão instaladas as diferenças, sejam elas pequenas ou grandes, entre as indústrias de um mesmo sítio arqueológico ou uma mesma região. Por exemplo, os objetos unifaciais de sessão plano-convexa são uma imagem mental (PELEGRIN, 1986 [1995]) presente em determinados grupos humanos, desde o final do período Pleistoceno, em grande parte do Brasil e da América do Sul. Tal ideia vai se perpetuar até o Contato com os europeus ou neo-brasileiros. Entretanto, a ideia de um instrumento com uma face plana e outra convexa guarda em si muitas distinções e pode não se tratar de um objeto único. Tanto as escolhas de matérias-primas, muitas vezes distintas, quanto a utilização de diferentes técnicas de preparação da debitagem para a retirada dos suportes, assim como as buscas de dimensões volumétricas do suporte e do instrumentos terminados, ou, ainda, as escolhas variadas na evolução da façonagem, do retoque e a retomada de tais instrumentos, etc., têm demonstrado que, frequentemente, estamos diante de 
instrumentos e de cadeias operatórias distintas (RODET, 2006). A ideia volumétrica ou a morfologia podem ser parecidas quando observamos o instrumento superficialmente, mas a análise minuciosa das distintas fases de produção (quais técnicas foram utilizadas, quais tipos de retoques, quais matérias-primas, etc.), demonstra, muitas vezes, tratar-se de projetos totalmente diferentes.

$\mathrm{Na}$ evolução e renovação das problemáticas da Escola Francesa, outros conceitos vieram se juntar a esses já estabelecidos, na intenção de compreender aspectos não só tecno-econômicos, mas, principalmente, comportamentais. Um deles é a noção de economia da debitagem, demonstrado por J. Tixier e M. L. Inizan (INIZAN, 1980 [1984]; etc): certos suportes foram escolhidos para desenvolver determinados instrumentos. Essa noção, enriquecida pouco a pouco com outros conceitos, tais como, economia dos utensílios (CAHEN et al., 1980), economia da matéria-prima (PERLÈS, 1980, INIZAN, 1980 [1984]) e seu aprovisionamento (PÉTROQUIN \& PÉTROQUIN, 2002), tipologias de sítios (sítios de produção, consumo, acampamentos distintos, etc.), a cognição e o conceito de savoir-faire (PELEGRIN, 1991), têm contribuindo para formar um arcabouço importante na compreensão das intenções e das escolhas dos grupos passados no que se refere aos processos produtivos das indústrias lascadas.

Nessa abordagem, os estados técnicos das peças têm um lugar importante em função do aporte que ele traz. Uma das contribuições de J. Pelegrin aos estudos de coleções líticas tem permitido entender, a partir da observação minuciosa dos núcleos e das peças retocadas, de suas alterações ao longo do tempo, de seus distintos estados técnicos, de seus variados volumes, os objetivos do lascamento. Os restos brutos de lascamento, mesmo na ausência dos instrumentos lascados, possibilitam o reconhecimento das escolhas tecnológicas desses grupos, suas intenções, seus Projetos (PELEGRIN, 1986 [1995]; INIZAN et al., 2017). A noção de estado técnico dos instrumentos ou núcleos é um elemento fundamental no conceito de cadeia operatória. $\mathrm{O}$ estado em que um arqueólogo encontra um utensilio (retocado, façonado, fragmentado, etc.) corresponde certamente a um momento (ou momentos) de sua trajetória. É como se o arqueólogo estivesse diante de uma fotografia do passado, de um fragmento, de uma pequena parte da história desse instrumento. É fundamental que o pré-historiador tenha conhecimento de leitura tecnológica para entender o lugar desse "momento" ao longo do processo produtivo do instrumento. No caso dos planoconvexos, por exemplo, instrumentos de vida longa, suas evoluções tecnológicas podem (ou não) resultar em morfologias muito diferentes daquelas do início de sua produção, sendo de fato suas morfologias, muitas vezes, somente expressões de um mesmo objetivo, mas em momentos distintos, ou seja, em estados-técnicos diferentes. Por outro lado, as indústrias líticas brasileiras apresentam grande variedade de intenções na produção de instrumentos realizados sobre lascas alongadas. Assim, podem coexistir em um mesmo sítio arqueológico, ou em conjuntos de sítios próximos, instrumentos de seção mais e menos plano-convexas provenientes de distintas cadeias operatórias. A aplicação da análise tecno-econômica, considerando as ações técnicas, as quais são relacionadas às intenções (mais ou menos claras ou, ao contrário, específicas - PELEGRIN, 1986 [1995], 2005; etc.), desde a escolha da matéria-prima, do suporte, suas transformações nas distintas fases de produção, seus bordos, suas funções esperadas ou desejadas, tem tido resultados excelentes nas nossas pesquisas brasileiras (PROUS et al., 1994; FOGAÇA, 2001; RODET, 2006; BUENO, 2007; DUARTE-TALIM, 2012; entre muitos outros). Trata-se de, para o pré-historiador, observar as regras inscritas nas coleções: quais elementos se repetem e podem ser observados? A procura por um suporte alongado, bordos abruptos com retoques escamosos, bordos denticulados, superfícies paralelas, etc. 
No Brasil, de uma maneira geral, em um sítio arqueológico, podem coexistir várias cadeias operatórias: produções de unifaciais de seção plano-convexa, distintos; produção de unifaciais achatados; produção bifacial de pontas de projétil e outros; produção de instrumentos simples, pouco trabalhados, além da produção de lascas que serão utilizadas diretamente sem transformação (SCHMITZ et al., 2004; RODET, 2006; BUENO, 2007; ISNARDIS, 2009; DUARTE-TALIM, 2012; etc.).

Noções incorporadas à Escola Francesa e seus conceitos buscam desenvolver estudos específicos sobre a evolução e a função dos gumes sobre os utensílios, trata-se da análise tecno-funcional (LEPOT, 1993; BOEDA, 1997). A intenção é buscar a funcionalidade dos instrumentos através da análise do potencial que pode estar inscrito nos gumes. Tais análises têm sido aplicadas em indústrias brasileiras principalmente nas regiões central e nordeste do país (VIANA, 2005; FOGAÇA \& LOURDEAU, 2008; LOURDEAU, 2010; entre outros)

Mais uma vez, nota-se a flexibilidade e a robustez do pensamento da Escola Francesa, que, por um lado, busca rigidez e sistematização e, por outro, é elástico e permite sempre noções novas que vão se complementando e reforçando o arcabouço inicial.

Do ponto de vista da economia e das questões comportamentais dos grupos passados, esse conjunto de conceitos e problemáticas permitiu estruturar as análises tecnológicas dentro de uma perspectiva que vai buscar diretamente os i. objetivos da debitagem através do estudo dos instrumentos e da aquisição do suporte (representantes primeiros dos objetivos da debitagem); ii. a evolução desses instrumentos no tempo e no espaço (quais as técnicas utilizadas, qual é a procura volumétrica, em qual estado técnico o instrumento se encontra); iii. as matérias-primas escolhidas para produzir as diversas indústrias; iv. as distintas classes de brutos de debitagem presentes e ausentes dos sítios; etc. Esses elementos, assim organizados e, classificados hierarquicamente de um ponto de vista tecno-econômico, permitem entender quais partes das cadeias operatórias estão presentes dentro de um sítio, em quais camadas estratigráficas e em quais matériasprimas foram realizadas.

\section{REFLEXÕES FINAIS E CONTEXTUALIZAÇÃO COM DADOS DE SITIOS VIZINHOS}

No caso específico desse estudo, a abordagem tecno-econômica permitiu destacar uma série de elementos culturais presentes nos vestígios líticos das quadras analisadas do sítio GO-JA-03 e em instrumentos do sítio GO-JA-14.

De uma maneira geral, vale lembrar que estamos falando de um grande abrigo que tem aproximadamente $80 \mathrm{~m}$ de desenvolvimento e até $14 \mathrm{~m}$ de profundidade. $\mathrm{O}$ material aqui analisado ocupa aproximadamente uma área de 2,5 x 2,5 m, ou seja, uma parte muito pequena do sítio. Entretanto acreditamos que este setor teve uma função específica em relação ao espaço de vida do abrigo, em todo caso, durante as ocupações mais antigas, tendo sido utilizado como local de produção lítica. A grande quantidade de restos brutos de debitagem, o baixo número de instrumentos exumados, a presença de distintas fases de debitagem, façonagem e retoque são elementos que apontam para uma atividade de lascamento intensa no setor. Nesse sentido, a coleção é representativa de características tecnológicas e econômicas procuradas pelos grupos que frequentaram o local, sem esquecer que, muito provavelmente, estamos diante de porções de cadeias operatórias distintas, um amas de débitage.

A presença de grandes lascas com face inferior plana, sem acidentes, pequenos talões com procedimentos técnicos específicos apontam, de um lado, o controle excepcional dos lascadores durante o lascamento e, de outro, a utilização de técnicas muito especificas, como a percussão com pedra macia e a percussão direta orgânica 
tangencial. Ainda, a presença de grandes lascas com certas características (plano de percussão provisório, lascas mais espessas com sub-córtex, etc.) durante o processo de debitagem indica que as mesmas têm como principal função, calibrar o núcleo, colocá-lo na forma necessária para produzir um suporte ideal, desejado. A criação de planos de percussão transitórios, que serão em seguida reinseridos na debitagem, na busca de um plano-percussão ou de uma superfície de debitagem apropriados (larga, longa, sem acidentes refletidos, sem córtex, com uma determinada cintragem, etc.) são elementos que conformam esse alto nível de savoir-faire no conjunto analisado. Por outro lado, tais lascas remetem ao início do processo de debitagem. Os núcleos, não analisados neste estudo, podem chegar a $50 \mathrm{~cm}$ de comprimento, o que é extremamente coerente com as lascas de grandes dimensões (uma das lascas do conjunto mede $30 \times 25 \times 10 \mathrm{~cm}-$ SCHMITZ et al., 2004).

De acordo com P.I. Schmitz e colegas (1989; 2004), no platô acima dos sítios (pelo menos em um sítio de cada grupo), foram observados locais de coleta e de retirada matéria-prima, sendo as torres acima do GO-JA-03 um dos locais de exploração. Em um dos sítios do grupo B, GO-JA-21a, nota-se grandes blocos ou núcleos que se encontram no limite da área sombreada pelas árvores. Neste local, ao que parece, eram realizadas as primeiras fases do processo de debitagem: limpeza do córtex de grandes blocos corticais de arenito silicificado, em seguida a retirada de suportes alongados, largos e espessos que servirão de núcleos ( $71 \times 53 \times 37 \mathrm{~cm} ; 50 \times 40 \times 30 \mathrm{~cm} ; 40 \times 38 \times 23 \mathrm{~cm}$ ou mais explorados $30 \times 26 \times 20 \mathrm{~cm} ; 24 \times 16 \times 19 \mathrm{~cm} ; 23 \times 21 \times 13 \mathrm{~cm}$ ), os quais serão transportados para as áreas abrigadas. Blocos, núcleos e dezenas de percutores em arenito de dimensões variadas foram encontrados no local $(32 \times 19$ x $8 \mathrm{~cm} ; 27$ x 21 x $10 \mathrm{~cm} ; 17$ x 12 x $8 \mathrm{~cm} ; 9,5$ x 13 x $8 \mathrm{~cm}$, etc. - SCHMITZ et al., 1989, 2004). Entretanto não é possível relacionar diretamente esses vestígios com aqueles dos sítios aqui estudados. Essas áreas podem ter sido exploradas pela qualidade da matéria-prima ao longo de todo o Holoceno.

Ao que parece, no que se refere à exploração do maciço, há um descolamento natural de blocos das paredes expostas à amplitude térmica: dias muito quentes em oposição a noites frias (SCHMITZ et al., 1989, 2004). Ou ainda, a própria evolução geomorfológica do maciço arenítico. Contudo uma técnica possível para a retirada de blocos das paredes é a utilização do fogo. Fazer fogueiras em um setor da parede do maciço, fará, inevitavelmente, desprender placas de dimensões variadas. Algumas das grandes lascas analisadas apresentaram vestígios de contato térmico nas duas superfícies, talvez em função desse tipo de processo. Em contrapartida, em alguns abrigos foi possível observar negativos de retiradas realizadas diretamente na parede encaixante do abrigo (paredes mais horizontais), a partir de golpes, como é o caso do GO-JA-01 (A. Da Costa, com. pessoal).

Uma matéria-prima de qualidade para o lascamento, como é o caso do arenito altamente silicificado, da rocha encaixante do abrigo GO-JA-03, certamente atraiu para a área lascadores com um alto nível de conhecimento e domínio do lascamento. E, junto aos lascadores experientes, muito provavelmente, havia os aprendizes, que frequentavam o lugar tanto para observar os lascadores mais velhos, com alto nível de savoir-faire, quanto para treinar suas próprias habilidades, como indicam as lascas e os instrumentos, que contêm as mesmas estruturas desejadas (dimensões volumétricas, utilizações das mesmas técnicas, etc.), mas apresentam erros e acidentes em uma matéria-prima de menor qualidade para o lascamento.

O material exumado dessa escavação nos mostra claramente a intenção ou as intenções dos lascadores. Uma delas, talvez a mais clara, é a procura de produtos alongados com uma grande disponibilidade de gumes, retilíneos, convexos, mais e menos abruptos, os quais permitem uma utilização como tal ou ainda suportam várias 
transformações. Trata-se de um objeto de vida longa, estabilizado, nos quais aparecem duas superfícies integradas e interdependentes, presentes desde a sua concepção, uma plana outra mais e menos convexa. Elas trarão um equilíbrio à debitagem e depois à façonagem, e o instrumento finalizado guardará em si sua própria reserva de matériaprima e de possibilidades, que serão utilizadas ao longo de sua vida.

Outros elementos merecem destaque neste estudo, como os dois instrumentos sobre lascas alongadas, pouco espessas, com retoques que complementam e delineiam os bordos. Eles contribuem e complementam essa compreensão das intenções desses primeiros grupos que frequentaram a região, quais sejam, a busca por esses produtos sobre suporte alongado, realizados com técnicas e intenções distintas, que nos remetem a um lascamento controlado, sem acidentes.

De fato, as distintas cadeias operatórias presentes nessas primeiras ocupações do abrigo demonstram a diversidade dos modos de produção, dos projetos e das intenções dos atores que deixaram suas marcas impressas nas rochas lascadas. Se inserirmos esses resultados àqueles obtidos mais recentemente para o sítio arqueológico GO-JA-01 (LOURDEAU, 2010), distante aproximadamente $25 \mathrm{~km}$ ao norte do sítio GO-JA-03, nota-se algumas semelhanças: por exemplo, os suportes da maior parte dos instrumentos inteiros apresentados por A. Lourdeau (2010; 2016) são lascas que tendem a ser alongadas, os instrumentos parecem ter uma vida extensa e trazem em si uma reserva de matéria-prima que permite diversas transformações. Nota-se, por vezes, negativos vestigiais na face superior, anteriores à retirada do suporte, que estruturam a façonagem. Os gumes criados desde o início da produção são, em geral, paralelos, mais e menos retilíneos, sendo mais e menos abruptos, interligados por um gume convexo em pelo menos uma das extremidades do instrumento. Por outro lado, a obtenção do suporte é distinta do que acontece no GO-JA-03. De acordo com A. Lourdeau (2010, 2016), quando foi possível fazer a leitura tecnológica, nota-se que os suportes foram retirados por percussão direta dura. $\mathrm{O}$ que é bem distinto dos suportes com presença de técnicas e tratamentos específicos, encontrados no Corte IV do GO-JA-03. Ainda, como distinção entre as duas coleções, nota-se que os suportes pouco espessos, longos, assim como os núcleos e a grande quantidade de lascas de façonagem e retoque, também estão ausentes dessa área estudada por A. Lourdeau no sítio GO-JA-01. Por outro lado, de uma maneira geral, o seu estudo sistemático dos gumes dos instrumentos aponta para gumes com potenciais de utilizações variados. Tal resultado pode ser um complemento ao que foi observado no material aqui apresentado, pois o nosso baixo número de peças terminadas não nos deixa diagnosticar (com resultados representativos) as transformações realizadas nos gumes. É possível, como afirma A. Lourdeau (2010), que as modificações que foram realizadas nos instrumentos por ele analisados estejam já inseridas desde a sua concepção.

J. C. Moreno de Sousa (2014) retomou 25\% do material por nós analisado, e seus resultados confirmam a tendência da indústria: produção de lascas suporte alongadas ("laminares"), que serão façonadas e retocadas dentro do sítio, conformando instrumentos unifaciais. Concordando com A. Lourdeau (2010), os instrumentos produzidos apresentam gumes potenciais mais e menos aptos a diferentes usos, como cortar ou raspar (MORENO DE SOUSA, 2014).

Acreditamos que o Projeto, a Intenção dessa produção é muito mais elaborada e diversificada do que possa deixar pensar uma análise rápida de um instrumento unifacial com essas características. O que podemos afirmar no final de nossas análises, no que concerne aos instrumentos de seção plano-convexa exumados desse sítio ou de outros do Brasil Central, como é o caso daqueles do vale do rio Peruaçu (RODET, 2006) ou do rio Jequitaí (BASSI \& RODET, 2011; NOLASCO, 2015), é a existência de instrumentos 
em estados técnicos distintos, ou seja, sobre alguns é possível observar a lasca suporte quase completa, demonstrando que a façonagem fez pouca transformação no objeto (o instrumento estaria no seu início de vida). Outros, nos quais observam-se instrumentos que guardam parte das intenções iniciais (sejam elas: um setor mais espesso que outro, ângulos de 800 ou 700 nos gumes, uma das extremidades ou as duas ogivais, etc.), mas já em estado adiantado de utilização. Tratam-se de instrumentos em meia vida ou em final de vida, ou seja, em estados técnicos distintos. Essas transformações são esperadas e estão inscritas nos objetos desde a sua concepção. Por outro lado e, mesmo paralelamente, nota-se instrumentos que tem essa seção plano-convexa, mas que são projetos diferentes dos primeiros: podem ser instrumentos totalmente façonados, nos quais não há a presença de grandes negativos anteriores à debitagem na face superior, ou, ainda, uma classe de instrumentos com volumes mais e menos espessos e que apresentam, potencialmente, distintas utilizações nos diferentes gumes. A ideia de uma seção planoconvexa é certamente muito produtiva e interessante economicamente (está presente desde a passagem do período Pleistoceno para o Holoceno até o Contato com os europeus), e, a partir dela, os grupos desenvolveram projetos mentais distintos. Ela seria somente uma base já estabilizada e presente em grande parte da América do Sul, a partir da qual os grupos traduzem as suas distintas intenções.

Especificamente sobre a tecnologia lítica desses grupos humanos, chama à atenção um lascamento cuidadoso e controlado, muito bem estruturado, cujo objetivo era a produção de instrumentos determinados (unifaciais de secção plano-convexa alongados, bifaciais espessos, pontas bifaciais delgadas, instrumentos alongados pouco espessos, além de instrumentos retocado simples), sobre uma matéria-prima de excelente qualidade para o lascamento e abundante no setor. Sobre os instrumentos e seus restos de produção, foi possível observar a utilização de diferentes percutores (pedra dura, pedra macia e orgânico), utilizados com gestos distintos (percussão direta, percussão tangencial), além da constante preparação do plano de percussão (pequenas retiradas para ressaltar o ponto de impacto, abrasão e émoussé) e uma baixa taxa de acidentes elementos que sustentam uma indústria lítica elaborada.

Para ilustrar esse artigo, gostaríamos de apresentar uma descrição de Annette Laming-Emperaire (1978) sobre seu encontro com um dos últimos indígenas Xetá, do estado Paraná, na qual ela observa e descreve a utilização de um instrumento planoconvexo utilizado em parte de uma cadeia operatória de produção de um arco:

[...] quando o arco atinge uma certa espessura, Ayatukã escolhe um objeto em forma de lesma em seu saco de pedras lascadas. Tal objeto, curto e sem encabamento, é tomado pelas duas mãos como um plaina, o que força os dois pulsos de Ayatukã a ficarem próximos do dorso do objeto. Para evitar se machucar nas arestas da pedra, lascas de madeira, dispostas de cada lado da lesma, substituem o cabo. [...] Para reavivar seu objeto que apresenta um gume usado, ele bate delicadamente sobre a face inferior e plana e com um golpe maldado, ele quebra o objeto em dois. [...] Ele pega uma segunda lesma no seu saco (ele tem muitas), examina com cuidado seu gume, afia-o com cuidado, retira uma lasca com sua unha e continua a raspagem da madeira. [...] Os pés têm um papel importante neste trabalho que dura muitas horas. Durante quase todo o tempo, eles são posicionados simetricamente de um lado e de outro da madeira do arco, sobre o qual Ayatukã está assimetricamente assentado. [...] A maioria dos instrumentos em pedra do seu saco não foram utilizados, mas os dois que foram utilizados nesse trabalho, estão completamente amarelados pelo trabalho (LAMING-EMPERAIRE et al., 1978, tradução nossa).

Finalmente, entre esses grupos de sítios próximos, poderíamos pensar em locais que se complementam: produções sistemáticas de instrumentos em um sítio e consumo em 
outros. Contudo a quantidade de vestígios analisados no caso dessa pesquisa não nos permite fazer tal inferência. Os estudos sistemáticos da equipe do Instituto Anchietano indicam, por sua vez, que se trata de uma utilização racional do espaço, estável ao longo do tempo, onde eram ocupados grupos de abrigos e não abrigos isolados e que estes se complementavam: abrigos maiores (papel central ao longo das ocupações) e menores, mais e menos ensolarados, sempre próximos à água corrente, matérias-primas líticas diversificadas, presença de caça e de abundância vegetal. Em alguns deles, foi possível observar locais de exploração das jazidas de matérias-primas de excelente qualidade para o lascamento, em outros locais de produção lítica, em outros ainda instrumentos utilizados, inteiros, fragmentados, etc. (SCHMITZ et al., 2004). 


\section{REFERÊNCIAS BIBLIOGRÁFICAS}

BARRETO, Cristiana. 1999-2000. A construção de um passado pré-colonial: uma breve história da arqueologia no Brasil. Revista USP, São Paulo, no 44: 32-51.

BASSI, Luís Felipe. 2012. Tecnologia Lítica: Análise diacrônica dos níveis mais antigos do sítio arqueológico Bibocas II, Jequitaí - MG. Dissertação de Mestrado. Belo Horizonte, Universidade Federal de Minas Gerais. 286pp.

BASSI, Luís Felipe; RODET, Maria Jacqueline. 2011 [2017]. Abordagens tecnológicas do lascamento de cristal de quartzo. Apresentação e Resumo. Trabalho apresentado no XVI Congresso da Sociedade de Arqueologia Brasileira, Florianópolis. 2011. Resumo publicado em: FERNANDES, L. e DUARTE-TALIM, D. (orgs.) Tecnologia lítica na arqueologia brasileira: coletânea de (re)publicações. Belo Horizonte: Editor MHNJB-UFMG. 2017. p. 218-219.

BOËDA, Eric. 1990. De la surface au volume. Analyse des conceptions des débitages Levallois et laminaires. Paléolithique moyen et récent et Paléolithique supérieur ancien d'Europe. Actes $d u$ colloque international de Nemours, 9-11 mais 1988, (C. Farizy). Mémoire du musée de Préhistoire d'Ile de France, Nemour, $3: 63-68$.

BOËDA, Eric. 1997. Les plus vieilles industries de France. La France préhistorique. -Ed. Paris: Gallimard, v. 1: 34-45.

BOËDA, Eric; CLEMENTE-CONTE, Ignácio; FONTUGNE, Michel; LAHAYE, Christelle; PINO, Mario ; FELICE, Gisele Daltrini; GUIDON, Niède.; HOELTZ, Sirley; LOURDEAU, Antoine; PAGLI, Marina; PESSIS, Anne-Marie; VIANA, Sibeli; COSTA, Amélie; DOUVILLE, Eric; 2014. A new late Pleistocene archaeological sequence in South America: the Vale da Pedra Furada (Piauí, Brazil). Antiquity (Cambridge), v. 88 : 927-955.

BUENO, Lucas. 2007. Variabilidade tecnológica dos sítios líticos da região do Lajeado, médio rio Tocantins. Revista do Museu de Arqueologia e Etnologia - Universidade de São Paulo, Suplemento 4. $215 \mathrm{pp}$.

CAHEN, Daniel.; KEELEY, Lourence H.; VAN NOTEN, F; KARLIN, Claudine.1980. Méthodes d'analyse technique, spatiale et fonctionnelle d'ensembles lithiques. Helinivm, no 20: 209-259.

CALDERÓN DE LA VARA, Valentin. 1965-1966. Notícias preliminares sobre as sequências arqueológicas do médio São Francisco e da Chapada Diamantina, Estado da Bahia. Publicações avulsas: PRONAPA, Resultados Preliminares do 10 ano, 1965-1966. MPEG, Belém, n 6: 107-119.

CALDERÓN DE LA VARA, Valentin. 1969. Nota prévia sobre a arqueologia das regiões central e sudoeste do Estado da Bahia. PRONAPA, Resultados Preliminares do $2^{\circ}$ ano, 1966-967. Belém, Museu Paraense Emílio Goeldi, Publicações avulsas, n.10: 135-147.

CALDERÓN DE LA VARA, Valentin. 1983. As tradições líticas de uma região do baixo médio são Francisco (Bahia). Estudos de Arqueologia e Etnologia. Salvador, Universidade Federal da Bahia, Coleção Valentin Calderón, v.1:37-52.

CHAUCHAT, Claude. 1991. L'approche technologique dans une étude régionale : le Paijenien de la côte du Pérou. In: Centre de Recherche Archéologiques du CNRS (org.). 25 Ans d'études technologiques en préhistoire : bilan et perspectives - XIe Rencontres Internationales d'Archéologie et d'Histoire d'Antibes - Actes des rencontres. Éditions APDCA - Juan-les-Pin : 263-273.

CHAUCHAT, Claude; PELEGRIN, Jacques. 2004. Projectile point technology and economy; a case study from Paijan, North coastal Peru. 1. ed. Texas: Center for the Study of the First Americans. $138 \mathrm{pp}$.

CHAUCHAT, Claude; WING, Elisabeth; LACOMBE, Jean-Paul; DEMARS, Pierre.-Yves; UCEDA, Santiago; DEZA, Carlos. 2016. Prehistoria de la costa norte del Perú: el Paijanense de Cuspinique. Institut français d'études andines. 363pp. Disponivel em books.openedition.org/ifea/5156 Acesso em 21/02/2019. 
DA COSTA, Amélie. 2017. Rupture technique et dynamiques d'occupation au cours de l'Holocène moyen au Brésil. Tese de doutorado. Paris, Universitée Parix X. 390pp.

DIAS, Adriana Schmidt. 2003. Sistemas de Assentamento e Estilo Tecnológico: uma proposta interpretativa para a ocupação pré-colonial do alto vale do rio dos Sinos, Rio Grande do Sul. Tese de doutorado. São Paulo, Universidade de São Paulo. 401pp.

DIAS, Adriana Schmidt; BUENO, Lucas. 2013. The initial colonization of South America Eastern lowlands: Brazilian arhaeology contributions to settlement of America models. In: FRAF, K; KENTRON, C. V.; WATERS, M. (edts.) Paleoamerica odissey. Center for the studies of first Americans, Texas University, pp.339-357.

DILLEHAY, Tom D. 1999. The late Pleistocene cultures of South America. Evolutionary Anthropology, vol. 7, tomo 6: 206-216. Disponível em: https://onlinelibrary.wiley.com/doi/abs/10.1002/\%28SICI\%2915206505\%281999\%297\%3A6\%3C206\%3A\%3AAID-EVAN5\%3E3.0.CO\%3B2-G. Acesso em $20 / 03 / 2018$.

DILLEHAY, Tom D.; OCAMPO, Carlos; SAAVEDRA, José; SAWKCHI, Andre Oliveira; VEGA, Rodrigo M.; PINO, Mario; COLLINS, Michel B.; CUMMINGS, Linda Scott; ARREGUI, Iván; VILLAGRAN, Ximena S.; HARTMANN, Gelvam A.; MELLA, Mauricio; GONZÁLEZ, Andrea; DIX, George. 2015. New archaeological evidence for an early human presence at Monte Verde, Chile. PLoS ONE 10 (11): 1-27.

DUARTE-TALIM, Déborah. 2012. As indústrias líticas das ocupações ceramistas da Amazônia: Estudo do sítio PA-OR-127: Cipoal do Araticum, região de Porto Trombetas, estado do Pará. Dissertação de Mestrado. Belo Horizonte, Universidade Federal de Minas Gerais. 268pp.

DUARTE-TALIM, Déborah e RODET, Maria Jacqueline. Uma reflexão sobre a criança e a infância: em busca de indícios de crianças/aprendizes lascadoras na pré-história brasileira. In: LIMA, T. A. (org.). A (in)visibilidade de crianças no registro arqueológico. Teresina: Alínea Publicações Editora, no prelo.

FAGUNDES, Marcelo. 2007. Sistema de assentamento e tecnologia lítica: organização tecnológica e variabilidade no registro arqueológico em Xingó, Baixo São Francisco, Brasil. Tese de doutorado. São Paulo, Universidade de São Paulo. 634pp.

FERNANDES, Luydy. 2011. As lâminas de machado lascadas aratu de Piragiba -BA. Tese de doutorado. Salvador, Universidade Federal da Bahia. 401pp.

FERNANDES, Luydy e DUARTE-TALIM, Déborah (orgs.). 2017. Tecnologia lítica na Arqueologia Brasileira: Coletânea de (re)publicações. Belo Horizonte: MHNJB-UFMG Editor. 237pp.

FOGAÇA, Emílio. 2001. Mãos para o pensamento. A variabilidade tecnológica de indústrias líticas de caçadores-coletores holocênicos a partir de um estudo de caso: as camadas VIII e VII da Lapa do Boquete (Minas Gerais, Brasil - 12.000/10.500 B.P.). Tese de Doutorado. Porto Alegre, Pontifícia Universidade Católica do Rio Grande do Sul. 450pp. 2v.

FOGACA, Emílio; LOURDEAU, Antoine. 2008. Uma abordagem tecno-funcional e evolutiva dos instrumentos plano-convexos (lesmas) da transição Pleistoceno/Holoceno no Brasil Central. FUMDHAMentos, v. 7: 260-293.

HOGG, Alan, G.; HUA, Quan; BLACKWELL, Paul G.; NIU, Mu; BUCK, Caitlin E.; GUILDERSON, Thomas P.; HWATON, Timothy J.; PALMER, Jonathan G.; REIMER, Paula J.; REIMER, Ron W.; TURNEY, Christian S. M.; ZIMMERMAN, Susan R. H. 2013. SHCal13 Southern Hemisphere Calibration, 0-50,000 Years cal BP. Radiocarbon, 55 (4): 1889-1903.

INIZAN, Marie-Louise. 1980 [1984]. Séries anciennes et économie du débitage. In: TIXIER, J. (org.). Préhistoire et technologie lithique. Journées du 11-12-13 mai 1979. Centre de Recherches Archéologiques du C.N.R.S., Valbonne: 28-30.

INIZIAN, Marie-Louise; REDURON-BALLINGER, Michelle; ROCHE, Hélène; TIXIER, Jacques. 2017. Tecnologia da pedra lascada. Ed. Revisão, atualizada e ampliada com definições e 
exemplos brasileiros por RODET, M. J. e MACHADO, J. R. Belo Horizonte: Museu de História Natural e Jardim Botânico da UFMG. 210pp.

ISNARDIS, Andrei. 2009. Entre as Pedras: as ocupações pré-históricas recentes e os grafismos rupestres de Diamantina, Minas Gerais. Tese de doutorado. São Paulo, Universidade de São Paulo.279pp.

KLARIC, Laurent (ed.). 2018. The prehistoric apprentice: investigating apprenticeship, know-how and expertise in prehistoric technologies / L'apprenti préhistorique: appréhender l'apprentissage, les savoirfaire et l'expertise à travers les productions techniques des sociétés préhistoriques. Brno: The Czech Academy of Sciences, Institute of Archaeology. 375pp.

KOOLE, Edward, K. M. 2014. Entre as tradições planálticas e meridionais: caracterização arqueológica dos grupos caçadores coletores a partir da análise de sete elementos e suas implicações para a ocupação pré-cerâmica da Região Cárstica do Alto São Francisco, Minas Gerais, Brasil: cronologia, tecnologia lítica, subsistência (fauna), sepultamentos, mobilidade, uso do espaço em abrigos naturais e arte rupestre. Tese de Doutorado. Universidade de São Paulo. 564 pp.

LAMING-EMPERAIRE, Annette, MENEZES, Maria José, ANDREATTA, Margarida Davina. 1978. O trabalho da pedra entre índios Xetá, Serra dos Dourados, Estado do Paraná. Coleção Museu Paulista, Série Ensaios, São Paulo, USP, 2: 11-82.

LEPOT, M. 1993. Approche techno-fonctionnelle de l'outillage lithique moustérien: essai de classification des parties actives en termes d'efficacité technique. Application à la couche M2e sagittale du Grand Abri de la Ferrassie (fouille Henri Delporte). Dissertação de Mestrado. Paris, Université Paris Ouest Nanterre La Défense.260pp.

LEROI-GOURHAN, André. 1943 [1971]. Évolution et techniques: L'homme et la matière. Paris: Éditions Albin Michel. 348pp. (Sciences d'aujourd'hui).

LEROI-GOURHAN, André. 1945 (1973]. Milieu et techniques. Paris: Éditions Albin Michel. 480 pp. (Sciences d'aujourd'hui).

LEROI-GOURHAN, André. 1964. O gesto e a palavra. 1- Técnica e linguagem. Lisboa, Vila Nova de Gaia, Rio de Janeiro: Edições 70, LDA. 237pp.

LOURDEAU, Antoine. 2010. Le techonocomplex Itaparica: définition tecno-fonctionnelle des industries a pièces façonnées unifacialement à une face plane dans le centre e le nord-est du Brésil pendant la transition Pléistocène-Holocène e Holocène ancien. Tese de Doutorado. Paris, Université de Paris Ouest Nanterre La Defense. 477pp.

LOURDEAU, Antoine. 2016. Industries lithiques du centre et du nord-est du Brésil pendant la transition Pléistocène-Holocène et l'Holocène ancien: la question du Technocomplexe Itaparica. L'Anthropologie, 120: 1-34.

MACHADO, Juliana de Resende. 2013. Au-delà du São Francisco: analyse technologique de l'industrie lithique du site Praça de Piragiba, Brésil. Dissertação de Mestrado. Paris, Université de Paris Ouest Nanterre La Defense.146 pp.

MAGET, Marcel. 1953 Guide d'étude directe des comportements culturels. Paris: CNRS. 278pp.

MARTINS, Gilson Rodolfo; KASHIMOTO, Emília Makiko. 2012. 12.000 anos: arqueologia do povoamento humano no nordeste de Mato Grosso do Sul. Campo Grande: Life Editora.192pp.

MAUSS, Marcel. 1947. Manuel d'ethnographie. Paris: Petite Bibliothèque Payot. 211pp.

MORENO DE SOUSA, João Carlos. 2014. Cognição e Cultura no mundo material: Os Itaparicas, os Umbus e os "Lagoassantenses". Volume 1 e 2. Dissertação de Mestrado. São Paulo, Universidade de São Paulo. 200 / 500pp.

NEWCOMER, Mark H. 1976. Spontaneous retouch. In : Second International Symposium on Flint : 62-64. Maastricht : Nederlandse Geologische Vereniging (Staringia; 3) : 62-64. 
NOLASCO, Raquel Caldas. 2015. Se misturar, separa? Análise tecnológica de indústrias líticas de quartzo de Jequitaí, Minas Gerais. Monografia de conclusão de curso. Belo Horizonte, Universidade Federal de Minas Gerais.160pp.

OSORIO, Daniela Paz; JACKSON, Donald; UGALDE, Paula C.; LATORRE, Cláudio; DE POLHOLZ, Ricardo; SANTORO, Calogero. 2011. Hakenasa Cave and its relevance for the peopling of the southern Andean Altiplano. Antiquity, no 85: 1194-1208.

OSORIO, Daniela Paz; CAPRILES, José M.; UGALDE, Paula C.; HERRERA, Katherine A.; SEPÚLVEDA, Marcela; GAYO, Eugênia M.; LATORRE, Claúdio; JACKSON, onald.; DE POLHOLZ, Ricardo; SANTORO, Calogero. 2017. Hunter-gatherer mobility strategies in the High Andes of Northern Chile during the Late Pleistocene-Early Holocene transition (ca.11,5009500 cal b.p.). Journal of Field Archaeology: 1-13. Disponível em: http://dx.doi.org/10.1080/00934690.2017.1322874. Acesso em 22/03/2018.

PELEGRIN, Jacques. 1986 [1995]. Technologie lithique: une méthode appliquée à l'étude de deux séries du Périgordien ancien (Roc Combe, couche 8- La Côte, niveau III). Tese de Doutorado. Paris, Université de Paris X. 586 p.

PELEGRIN, Jacques. 1991. Les savoir-faire: une très longue histoire. Terrain, $\mathrm{n}^{\circ} .16$ - Savoir-faire. 9pp. Disponível em: http://journals.openedition.org/terrain/3001. Acesso em: 20/12/2017.

PELEGRIN, Jacques. 2000. Les techniques de débitage laminaire au Tardiglaciaire : critères de diagnose et quelques réflexions. Table-ronde de Nemours, 2000, Nemours. L'Europe centrale et septentrionale au Tardiglaciaire. Confrontation des modèles régionaux de peuplement. Actes de la table-ronde de Nemours, mai 1997. Nemours: APRAIF, v. 7 : 73-86.

PELEGRIN, Jacques. 2005. Les pierres taillées: un historique de leur apport à l'archéologie. In: WRIGHT, J. D. (ed. chef.). International Encyclopedia of Social and Behavioral Sciences, 2 ed., vol. 14. Oxford: Elsevier. 8pp.

PERLÈS, Catherine. 1980. Economie de la matière première et économie du débitage: deux exemples grecs. Préhistoire et Technologie lithique., J. Tixier (dir.), Journées d'Etudes, 1, Paris, 11-13 juin, Editions CNRS, Publ. URA 28 du CRA : 37-41.

PÉTROQUIN, Pierre; PÉTROQUIN, Anne-Marie. 2002. Ecologie d'un outil: la hache de pierre en Irian Jaya (Indonésie). Monographie du CRA 12. Paris: CNRS Editions.: 21-81.

PHILIPPS, P.; WILLEY, G. R. 1953. Method and theory in American archaeology: an operational basis for culture-historical integration. American Anthropologist, vol. 55, $\mathrm{n}^{\circ} .5$, parte $1: 615-633$.

PIGEOT, Nicole. 1991. Réflexions sur l'histoire technique de l'homme: de l'évolution cognitive à l'évolution culturelle. Paleo Revue d'archéologie préhistorique, Paris: Société des amis du Musée National de Préhistoire et de la Recherche Archéologique, no 3: 167-200.

PROUS, André, FOGAÇA, Emílio; ALONSO, Márcio. 1994 As últimas indústrias líticas do vale do Peruaçu, MG. Revista de Arqueologia. São Paulo, Sociedade de Arqueologia Brasileira, v.8, n.2: 49-64. (Anais da 7' Reunião Científica da Sociedade de Arqueologia Brasileira).

RAMOS, Hernani Gomes da Cunha. 2004. O ciclo do chifre do cervo-do-pantanal:Aspectos ecológicos e reprodutivos. Dissertação de Mestrado. Jaboticabal, Universidade Estadua Paulista. $101 \mathrm{pp}$.

RAMSEY, Christopher Bronk. 2009. Dealing with Outliers and Offsets in Radiocarbon Dating. Radiocarbon, 51 (3): 1023-1045.

RAVINES, Rogger H. 1967. El abrigo de Caru y sus relaciones culturales con otros sitios tempranos del sur del Peru. Nawpa Pacha, no ${ }^{\circ} .59-57$.

RAVINES, Rogger H. 1972. Secuencia y cambios en los artefactos líticos del sur del Peru. Revista del Museo Nacional, t. XXXVIII : 133-164. 
RODET, Maria Jacqueline. 2006. Étude Technologique des industries lithiques taillées du nord de Minas Gerais, Brésil : depuis le passage Pléistocène/Holocène jusqu'au contact - XVIIIème siècle. Tese de Doutorado. Paris, Université Paris X, Nanterre. 516pp.

RODET, Maria Jacqueline. 2009. O estudo tecnologico das industrias liticas da baciad do rio Peruacu: cadeias operatórias, métodos de debitagem, técnicas de lascamento. Arquivos do Museu de Historia Natural e Jardim Botanico, v.19 : 415-440.

RODET, Maria Jacqueline; DUARTE-TALIM, Déborah; BASSI, Luís Felipe. 2011. Reflexões sobre as primeiras populações do Brasil Central: "Tradição Itaparica". Habitus. Goiânia, vol. 9 (1): 81-100.

RODET, Maria Jacqueline.; DUARTE-TALIM, Déborah; SANTOS JUNIOR, Valdeci dos. 2013. Cadeia operatória e análise tecnológica: uma abordagem metodológica possível para as indústrias líticas lascadas da América do Sul (exemplo das pontas de projétil do nordeste do Brasil). Cuadernos del Instituto Nacional de Antropologia y Pensamiento Latinoamericano - Series Especiales, No1 (2): 264-278.

RODET, Maria Jacqueline e DUARTE-TALIM, Déborah. 2013. Crianças, aprendizes, impropriedades ou inabilidades: os acidentes de lascamento das indústrias líticas do Brasil Central (exemplo do norte do estado de Minas Gerais). Revista do Museu de Arqueologia e Etnologia. Universidade de São Paulo, nº. 23: 129-138.

RODET, Maria Jacqueline; DUARTE-TALIM, Déborah; PELEGRIN, Jacque; SCHMITZ, Pedro Ignácio. La producción de grandes soportes alargados en las ocupaciones antiguas de Serranópolis, Brasil Central. No prelo.

SANTORO, Calogero; CHACAMA, Juan Miguel. 1984. Secuencia de asentamientos precerámicos del extremo norte de Chile. Estudos Atacameños, nº. 7: 71-84.

SCHMITZ, Pedro Ignácio; BARBOSA, Altair Sales; JACOBUS, André Luiz; RIBEIRO, Maira Barberi. 1989. Arqueologia nos cerrados do Brasil Central - Serranópolis I. Pesquisas, Antropologia, Unisinos, Rio Grande do Sul, no 44. pp.208.

SCHMITZ Pedro Ignácio; ROSA, André Osório; BITENCOURT, Ana Luísa Vietti. 2004. Arqueologia nos cerrados do Brasil Central - Serranópolis III. Pesquisas, Antropologia, Unisinos, Rio Grande do Sul, n 60. pp.287.

TIXIER, Jacques. 1967. Procédés d'analyse et questions de terminologie concernant l'étude des ensembles industriels du Paléolithique récent et de l'Epipaléolithique dans l'Afrique du NordOuest. In: BISHOP, W. W. e CLARK, D. (eds.). Background to evolution in Africa. Chicago: London: The University of Chicago Press, pp.771-820.

TIXIER, Jacques.1980. Préhistoire et Technologie lithique. Journées des 11-13 mai 1979, J. Tixier (dir.). Cahier $1,2^{\text {ème }}$ édition. Valbone : CNRS, URA 28, 59pp.

VIANA, Sibeli Aparecida. 2005. Variabilidade tecnológica do sistema de debitagem e de confecção dos instrumentos líticos lascados de sítios lito-cerâmicos da região do rio Manso/MT. Tese de doutorado. Porto Alegre, Pontifícia Universidade Católica do Rio Grande Do Sul. 348pp.

VIEIRA, Daniel; KER, João Carlos ; RODET Maria Jacqueline ; SCHAEFER Carlos Ernesto G. R.;TEIXEIRA, Wanceslau Geraldes. 2015. Pedoarqueologia em abrigo quartzitico, sitio Bibocas II, jequitai. Ocupacao humana no Holoceno tardio, bacia do São Francisco. Teoria es Sociedade (UFMG), v.23-1:167-197. 